\title{
Public Responsiveness to Victim's Recommendations in Their Sentencing Decisions: Role of Victim's Race, Victim Impact Statement and Judge's Instructions
}

Mary Elizabeth Talbot

Loyola University Chicago

Follow this and additional works at: https://ecommons.luc.edu/luc_theses

Part of the Social Psychology Commons

\section{Recommended Citation}

Talbot, Mary Elizabeth, "Public Responsiveness to Victim's Recommendations in Their Sentencing Decisions: Role of Victim's Race, Victim Impact Statement and Judge's Instructions" (2010). Master's Theses. 535.

https://ecommons.luc.edu/luc_theses/535

This Thesis is brought to you for free and open access by the Theses and Dissertations at Loyola eCommons. It has been accepted for inclusion in Master's Theses by an authorized administrator of Loyola eCommons. For more information, please contact ecommons@luc.edu. (c) (i) $\Theta \Theta$

This work is licensed under a Creative Commons Attribution-Noncommercial-No Derivative Works 3.0 License. Copyright @ 2010 Mary Elizabeth Talbot 


\title{
LOYOLA UNIVERSITY CHICAGO
}

PUBLIC RESPONSIVENESS TO VICTIM'S RECOMMENDATIONS IN THEIR SENTENCING DECISIONS: ROLE OF VICTIM'S RACE, VICTIM IMPACT STATEMENT AND JUDGE'S INSTRUCTIONS

\author{
A THESIS SUBMITTED TO \\ THE FACULTY OF THE GRADUATE SCHOOL \\ IN CANDIDACY FOR THE DEGREE OF \\ MASTER OF ARTS
}

PROGRAM OF APPLIED SOCIAL PSYCHOLOGY

BY

MARY E. TALBOT

CHICAGO, ILLINOIS

MAY 2010 



\section{LIST OF TABLES}

Table Page

1. Percentage of Sentencing Choices by Race Manipulation 34

2. Percentage of Participants Selecting Incarceration by Race 34

3. Sentencing Selections Based on VIS and Victim Perception 35

4. Logistic Regression Predicting Whether Prison Was Recommended 38

5. Mean Dollar Amounts Assigned to Offender Based on Manipulations $\quad 40$ 


\section{LIST OF FIGURES}

$\begin{array}{lll}\text { Figure } & \text { Page }\end{array}$

1. Sentencing Predictions Based on Manipulations 18

2. Proportion of Top Goals for Sentencing 42 


\begin{abstract}
A total of 191 participants completed the 2 (Race of victim: African American, Caucasian) x 2 (Content of Victim Impact Statement (VIS): Sentence Recommendation Only, Both Sentence Recommendation and Harm Statement) x 2 (Jury Guidelines for VIS: No guidance, Explicit instructions to weigh the harm statement with other aggravating and mitigating factors) between subjects factorial design study. The study assessed the relationship between the victim's race (African-American or Caucasian), the content of victim impact statements, and the judge's guidelines/instructions for interpreting/using the Victim Impact Statement (VIS) in the sentencing phase of a defendant's trial for burglary and aggravated battery. The results revealed race of the victim and judge's instructions had no impact on sentencing, or on the goals of sentencing as hypothesized. However, type of VIS was found to have significant effects on sentencing, goals of sentencing, as well as on the participants' perceptions of the victim. Finally, limitations and directions for future research are discussed.
\end{abstract}




\section{INTRODUCTION}

Over the course of the past year, several famous individuals have been in the media spotlight for making overtly racist comments. Specifically, in the past six months, Michael Richards of Seinfeld fame and media personality Don Imus, have made racist remarks towards African Americans and, as a result, lost their jobs and the respect of a large portion of the general population. This recent rash of racial utterances has started a media wildfire, and a campaign to eliminate racism and promote equality.

\section{RESEARCH ON RACE}

While the battle wages on in the media and the entertainment world, racism is rampant and prevalent in the criminal justice where justice and penalties continue to be unequally dispersed. Research in both Criminal Justice and Social Psychology shows that race plays a major role in who is suspected, arrested, and convicted. Research conducted by Engel (2005) showed that racial minorities, especially African Americans, were more likely to be stopped while driving and have the contents of their cars searched than Caucasian Americans. However, African American individuals were no more likely than Caucasian individuals to have contraband in their vehicles (anything from illegal substances to fire arms). Thus, showing there is no real justification for the increased search rates of African Americans and giving credence to the expression "driving while Black." 
Some researchers believe the deck is stacked against African-Americans. Research has shown that racial discrimination exists everywhere from initial charges through clemency decisions, including jury selection and sentencing (Baldus \& Woodworth, 2003; Baldus et al., 1990; Bowers et al., 2001; Gross \& Mauro, 1984).

Some research has shown that racial disparities between African-Americans and Caucasians do exist in the realm of sentencing. A study performed by the National Council on Crime and Delinquency (2000) found that African-American youths were six times more likely to be sent to juvenile prison than are Caucasian youths. When a violent crime is committed the African-American youths are nine times more likely to go to jail than their Caucasian counterparts. Furthermore the study found that African-American youths were a whopping 48 times more likely to go to jail for drug related offenses than Caucasian youths. A study on adult drug offenders showed that African-Americans received harsher penalties for drug offenses than Caucasians (Unnever, 1982). The results of a laboratory study conducted by Gordon, Bindrim, McNichols, and Waldron (1988) found that students provided significantly longer sentences to African-American defendants than Caucasians convicted of the same crime.

The effects of this racial bias are most pronounced when the perpetrator of the crime is African-American and the victim is Caucasian. More specifically, a AfricanAmerican defendant is much more likely to receive a harsher penalty for murdering a Caucasian individual, and much more likely to receive a death sentence in capital cases (Bowers \& Pierce 1980; Sorenson \& Wallace, 1995). Unah and Boyer (2001) 
investigated the death sentences in North Carolina and found that African-Americans who killed Caucasians were sentenced to death more often than any other group (Caucasian killers of Caucasians, African-American killers of African-Americans, or Caucasian killers of African-Americans). Research has also shown that AfricanAmericans convicted of rape (Zatz, 1984) and armed robbery (Thomson \& Zingraff, 1981) received stiffer penalties than did Caucasians convicted of these crimes.

It isn't just that African-American perpetrators receive more severe penalties for their crimes than Caucasian perpetrators. The racial bias extends towards the victims of crimes. Research has found that Caucasian victims are more highly valued than AfricanAmerican victims. This is certainly part of the reason that African-Americans are punished more harshly for killing Caucasians than other African-Americans. Research data extracted from court records and interviews with jurors that have participated in previous court cases have shown that individuals accused of killing Caucasians received more severe sentences than those who killed African-American individuals (Arkin, 1980; Bowers \& Pierce, 1980; Gross \& Mauro, 1984; Radelet, 1981).

While ample research has shown evidence of racial discrimination in drug crimes, rape, and capital murder cases, the research on the racial discrimination in sentencing or jury decision does not support the notion of widespread racial discrimination toward African-Americans. Unnever and Hembroff (1986), found that racial discrimination in sentencing was not significant factor in sentencing severity once social background characteristics, such as socio-economic status and prior criminal history were controlled. A similar study investigated offenders (of a variety of crimes including assault, burglary, 
and drug crimes) in California and found equitable sentences across races once they controlled for social background characteristics. Studies examining the consequences of race on the interpretation of prior criminal history have found conflicting findings; some studies have found that Caucasians were sentenced more severely if they had a prior criminal record while others have discovered that African-Americans were sentenced more severely (Zatz, 1984).

Given these aforementioned research findings, the pattern of racial discrimination is not clear cut. Racial discrimination is not a pervasive phenomenon across all crimes or geographical locations. While the results of some research suggest that racial discrimination is a thing of the past, other studies question these results. In a metaanalysis of 14 simulated juror studies, Sweeney and Haney (1992) found a significant effect for anti-African-American bias on jurors' sentencing decisions. Furthermore, Sweeney and Haney argued that the inconsistent findings may be attributed to methodological errors rather than the absence of racial bias.

At the very least, it is safe to say there is evidence showing that racial discrimination occurs in all realms of the criminal justice system It is not just that African-Americans are suspected more often and sometimes sentenced more severely for crimes, but that African-American victims are not valued as much as Caucasian victims. As a result, African-American victims and victim's families do not receive the same level of consideration in justice as Caucasian victims and their families. 
The abundance of studies supporting the notion of racial discrimination makes it nearly impossible to argue that such discrimination does not exist, at least in some cases and some crimes. The interesting question is now, not if there is racial discrimination, but asking why it exists, especially in a time where people seem so aware and (seemingly) striving to eliminate racial discrimination.

One possibility is that cultural stereotypes may contribute to the public's and jurors' decisions about appropriate sentences for convicted offenders. Stereotypes, in general, are an unconscious classification of individuals into broad categories (social, religious, racial etc.). An example of a well know stereotype that exists in this culture, is that African Americans (especially young males) are dangerous, aggressive, and violent. Social psychological literature has shown that individuals often use stereotypes (Cultural Stereotypes) to disambiguate ambiguous situations. In other words, when a person is doubt of the character or actions of a particular individual they will fall back on stereotypes (Duncan, 1976; Hilton \& von Hippel, 1990).

Cultural stereotypes are different from personal stereotypes in one key way. Cultural stereotypes are the wide-spread, widely known stereotypes, like the stereotypes regarding African American males mentioned in the previous paragraph; Cultural Stereotypes are not necessarily endorsed or in the conscious awareness of individuals when they are making decisions. For example, a person may not believe that all African American males are violent and aggressive, but know that this stereotype exists within their society. Even though a person may not personally believe in this stereotype, they, nevertheless, are influenced by it when making decisions about cases that contain 
ambiguous information, which is information that is open to multiple interpretations. Evidence for this supposition was provided by Duncan (1976), the results of Duncan's study showed that when Caucasians (males) and African-Americans (males) demonstrated the same behavior (pushing), African-Americans were judged as being more violent and aggressive than Caucasians.

A more recent study conducted by Correll, Park, Judd and Wittenbrink (2002) showed participants' pictures of Caucasian and African-American males holding various objects (some were guns and others were harmless objects such as cell phones) in various backgrounds.

The participants were then asked to act as law enforcement, and shoot individuals that were holding guns, thus posing a threat. Participants were randomly assigned to either a condition where they had ample time to determine whether the individual was holding a weapon or a short-interval of time where it was difficult to discern whether or not the object in the target's hand was a weapon. When given enough time to discern whether the target was a threat the participants did not make errors. However, in the short interval conditions participants shot erroneously at the African-American targets significantly more often than they did the Caucasian targets. The study controlled for racial stereotypes and the participants, in general did not endorse any racial stereotypes. However, the participants indicated that they were aware of the African-American equals violent and aggressive stereotype, thus lending more support to the influence of latent cultural stereotypes on racial discrimination. 
It could be argued that the participants in this study were, in fact, personally racist, but realized that it is not socially appropriate to endorse such beliefs and thus did not report them. However, while some Caucasian individuals in the participant pool may fall into this camp, it is not reasonable to assume that they all are racist. Even if they were, surely the African-American participants are not racist against their own race. It is most likely, that all participants are influenced by the ubiquitous cultural stereotype that African-Americans are violent, more violent than other members of other race. Gaertner and Dovidio (1986) argued that persons holding egalitarian beliefs in situations may act in a fair and impartial way when the norms against racial bias are clear, but will act in a racially biased way when the situation is ambiguous or conflicting. Essentially, people can understand that racial bias exists and that it is wrong to act biased when the situation is clear. However, when the situation is unclear people can revert to relying on stereotypes and biases when making decisions. According to Sweeney and Haney (1992), the norms of sentencing are ambiguous and the dimensions by which culpability is determined are subjective and not clearly defined by the law. Thus, sentencing deliberations are a fertile environment for culturally held stereotypes to emerge and affect decisions.

Racial discrimination against African Americans exists in the criminal justice system and the discrimination perseveres in part due to prevailing cultural stereotypes that depict African-American males as more aggressive and violent than their Caucasian counterparts. Furthermore, it is reasonable to assume that similar stereotypes perpetuate the de-valuation of African-American victims in the criminal justice system. 
This research proposal is aimed at understanding the gap in justice between Caucasian victims and African American victims. The literature on Victim Impact Statements (VIS) provided in the penalty/sentencing phases in trials may provide some solutions to level the playing field. VIS serves as a voice for the victims or crime, and helps the jurors to see the victim as human being rather than a faceless victim. Studies have shown that the greater harm caused is related to greater blameworthiness of defendant (Feigenson, Park, \& Salovey, 1997). Moreover, this research assesses whether the public supports restorative sentencing options for convicted offenders of burglary and aggravated battery, and whether this support generalizes to offenders who victimize African-American as well as Caucasian individuals.

\section{$\underline{\text { RESEARCH ON VICTIM IMPACT STATEMENTS }}$}

Victim impact evidence has been a hotly contested issue over the past two decades. In Booth v. Maryland, 1987 and Gather v. South Carolina, 1989, both capital murder trials, the courts ruled that information from the victim impact statement could not be used in making sentencing decisions. The courts stated that the VIS was not relevant in determining the culpability of the defendant. Three years later, the case of Payne v. Tennessee, 1991 overruled the earlier decisions that VIS may be admitted because it does function as an indicator of the blameworthiness of the defendant, because it elucidates the amount of harm the victim experienced as a result of the crime. However, Tennessee ruled the admissibility of victim impact statements should be on a case by case basis. This stipulation was overruled in 2004 when the Crime Victims' 
Rights Act was passed ensuring that all victims had the right to be heard at any public court proceeding.

Proponents of victim impact statements argue that allowing victims to speak or write about the damage that the crimes caused gives victims' a voice and a sense that justice has been done as well as aid the healing process for victims (Kilpatrick \& Otto, 1987). While others argue that VIS help to guide proportional retributive penalties, through providing information that allows judges to consider the pain and suffering that was caused to the victim (Erez, 1994).

Others see VIS having a prejudicial impact on the criminal justice system. Researchers have found that justice will become unbalanced because crimes will be sentenced based (partly) on the attributes of the victim rather than the crime itself (Hills \& Thompson, 1999).

The content of VIS can potentially bias the way juries weigh sentencing decisions. Greene (1999) found that jurors viewed the victim most favorably when VIS included a victim's personal characteristics (personal traits, occupation, etc), a specific statement of the harms caused by the crime (e.g. physical effects, psychological effects of the crime on the victim and the victim's family etc) and a sentence recommendation. Victims were viewed less favorably when some facets of this information were missing. It should be noted that character information is rarely admissible in VIS, if it has little to do with the harm done by the crime. Allowing character information is seen as prejudicial, because some victims will be seen as inherently more valuable than others (e.g. gang member vs. beloved clergy member). 


\section{PUBLIC VIEWS OF SENTENCING AND RESTORATIVE JUSTICE}

The public often has a vested interest in sentencing, because it is the most visible part of the criminal justice system (Roberts \& Stalans, 2000). It is commonly held that the public often favors harsher punishments for crimes than the criminal justice system actually imposes on offenders, because the public is often calling for severe punishments. However, research has shown that the public does not often favor harsher punishments than those imposed by judges. Diamonds and Stalans (1989) found that lay persons (the public) endorsed sentences that were no more severe than those handed down by judges, and in some cases they endorsed sentences that were less severe than sentences that judges imposed. Another study showed that criminal justice professionals favored a much harsher punishment (60 months) for an aggravated robbery case, compared to the public (36 months) (Mande \& Crouch, 1984).

Furthermore, some research suggests that the public are generally receptive to community-based sanctions, such as probation, restitution, and community service, than are criminal justice professionals. Research from a Colorado study showed that $14 \%$ of aggravated robbery offenders received community-based punishments were as $76 \%$ were incarcerated for their offenses. However, the public only favored incarceration $30 \%$ of the time and chose community based punishments such as probation almost $50 \%$ of the time (for a review of this literature see Roberts and Stalans, 2000). Moreover, another study showed that the public was far more supportive of community-based punishments than criminal justice professionals thought they (the public) would be (Immarigeon, 1986). 
Contrary to popular belief African-American and Caucasian citizens typically agree on sentencing severity. Secret and Johnson (1989) found that there has been a convergence of African-Americans' and Caucasians' attitudes toward sentencing since 1980. The differences that do emerge disappear when researchers controlled for socioeconomic, demographic, and political factors (Roberts \& Stalans, 2000). Essentially, the differences between races were not attributed to race itself, but to other factors.

While African-Ameircans' and Caucasians' views of sentencing are not different, research has shown that African Americans compared to Caucasians believe that there is more injustice in the criminal justice system (Henderson et al. 1997). Henderson and colleagues (1997) studied a stratified sample of Cincinnati residents. Results showed that African-American citizens were significantly more likely to believe that AfricanAmerican's are more likely to be stopped by police, given a ticket, jailed, and sentenced to death, than were Caucasian citizens. The effect of race in this study remained strong even when the researchers controlled for socio-economic status, demographic, and personal characteristics (including experience with the criminal justice system). This research showed that while Caucasians and African-Americans did not differ on sentencing severity they were different on their perceptions of racial injustice.

Restorative justice, in contrast to retributive justice, focuses less on the proportionality between crime seriousness and the severity of the penalty and places more importance on compensation for crimes and mending the relationships between victims and offenders. In other words, the goal of restorative justice is repairing the harms of the offense caused by re-establishing the victim to where they were before the offense 
(financially and mentally) as well as reconditioning the offender to a life-style free of crime.

Recent research has shown that the public tends to support restorative sentences, such as community service and restitution when the severity of the crime is low and favor more punitive sentences such as incarceration when the crime is severe (Gromet \& Darley, 2006). While there is not a plethora of research on public opinions of restorative justice, related studies seem to back Gromet's \& Darley's (2006) findings. Doble and Greene (2000) found that there was strong public support for "Community Reparations Boards" that work with judges to determine sentences for non-violent offenders. Furthermore, a German study found that public support for restorative justice wanes as the crimes become more serious.

Roberts and Stalans (2004), point to two psychological theories to help explain why the public supports restorative justice for perpetrators of less serious offenses; group value model (Lind, 1995; Lind \& Tyler, 1988) and attribution theory (Finchman \& Jaspers, 1980). The group value model holds that procedures that reaffirm group membership will be more highly regarded (Lind \& Tyler, 1988). Restorative justice allows both sides to be heard - both the victim and the offender - and is seen as being more fair. Furthermore, restorative penalties allow the offender to "make-up" for his crimes and repair his individual status within the group.

Attribution theory holds that people seek explanations for behavior. Research on attribution has shown that people make a distinction between responsibility and blameworthiness. This means that while one may be responsible for a crime, there are 
varying degrees to which a person is deserving of blame, depending on what, if any, external/mitigating factors are present. More serious crimes are often attributed to internal (permanent) characteristics of a person rather than external mitigating factors. This explains why some empirical studies have shown that a prior record is related to decreased support in restorative sanctions (Mattinson \& Mirrlees-Black, 2000). However, research has found that prior convictions only weaken the public's endorsement of restorative sentencing for violent offenders (Gandy, 1978; Gorczyk \& Perry, 1997).

Restitution is a restorative sanction where the offender repays the victim for the damages that his crimes have caused. Restitution or compensation has been viewed as an appropriate way to respond to criminal activity. Research has shown that restitution has typically been a highly publically supported restorative penalty (Gandy, 1978; Hudson, 1992). Doble (1994) asked the public to consider alternative sanctions/actions when dealing with offenders, the results showed that over $95 \%$ of the public advocated mandatory restitution. A study by Doble and Greene (2000) found that making restitution was the most important component of reparative boards. Furthermore, a study showed that people were about three times more likely to select restitution and probation over imprisonment for a recidivist burglar (Pranis \& Umbreit, 1992), thus showing that restitution is a more favorable sanction than incarceration.

While perhaps not as highly regarded as restitution, a term of community service has been a publically supported reparative sanction (Karp, 2001). Results of research in Canada revealed that when given the choice the public was willing to replace a term of 
imprisonment with a term of community service (Doob et. al, 1998). A national public survey in Canada asked participants to provide a sanction or sentence for an offender convicted of burglary. After selecting a sentence, the participants were then asked if they would rather impose a restorative sentence nearly two-thirds said "yes" (Doob \& Roberts, 1988). Similar results were replicated in Great Britain (Hough \& Robert, 2004).

Ample research has shown contrary to popular belief the public does not support more severe penalties for crimes than judges often impose in most cases. Additionally, it has been shown that the public sometimes favors less severe punishments as well as community-based punishments for convicted criminals. Research has also shown that differences in sentencing severity do not exist only across racial lines, but on socioeconomic, political, and demographic lines.

The present study will study the relationship between the victim's race whether the victim is African-American or Caucasian, and the content of the VIS (sentence recommendation only, harm statement only- specific harms that have resulted from the crime-, and both a sentence recommendation and a harm statement) on the public's sentencing recommendations. The third independent variable in the model will be the previously unstudied judge's instructions to the jury on how to interpret, process, or use the VIS (No guidelines, Tell the jury that it is the right of victim to have a voice in the sentencing; explicit instructions to weigh the VIS with the other aggravating and mitigating factors). 


\section{HYPOTHESES}

RESTORATIVE JUSTICE

It is hypothesized that restorative justice sentence choices will be viewed as less severe than prison sentences. The offender will be more likely to receive a restorative sanction when the participant judges his crime to be less severe than when his crime is rated as more severe. It is also expected that participants will select a restorative sanction when they place greatest importance on selecting a punishment that will repair the harm done to the victim and to the community, and ensuring that the offender takes responsibility for his offense and facilitating "law-abiding" behavioral changes in the offender. Those who select the retributive penalty (prison) will be more likely to place greater emphasis on the importance of deterrence (both for the offender and for other possible offenders) as well as on preventing further crimes, by the offender, while he is in prison.

\section{RACE, VICTIM IMPACT STATEMENTS, AND JUDGE'S INSTRUCTIONS}

In line with previous research it is hypothesized that there will be a main effect for race, the defendant will get a more severe penalty when his victim is Caucasian. In the absence of a clear sentencing choice (where there is an overwhelming amount of mitigating evidence to support a shorter/less severe sentence, or an overwhelming amount of aggravating factors to support a longer/more severe sentence), participants will be more likely to rely on stereotypes and heuristics to make sentencing decisions. This phenomenon is likely due the tendency for people to use stereotypes to form impressions of others and make sense of their behaviors (Wilson, Lindsey, \& Schooler, 2000). The 
differences in sanction severity will likely be mediated by stereotypical beliefs about the victim. Specifically, it is hypothesized that participants will be more likely to suggest that the African-American victim is more likely to have over-reacted to the crime, had a pre-existing emotional problem, and threatened the offender or acted in a way as to provoke the offender than the Caucasian victim. On the other hand, participants are more likely indicate that the Caucasian victim received serious emotional harm from the attack than did the African-American victim.

On the other hand, it is expected that when the VIS contains both a harm statement, explaining the specific harms that the offender's crime has caused and a sentence recommendation the defendant will receive a more severe sentence than when only a sentencing recommendation is proffered. Furthermore, it is hypothesized that disparity in sentencing between African-American and Caucasian victims should decrease in conditions where a victim impact statement, including harm statement is present. In other words, the gap in sentencing severity (for the offender) between African-American and Caucasian victims will be reduced when a impact statement about the specifics about the amount of harm done is included as opposed to a sentence recommendation only. Research has shown that the effect of stereotypes decrease when people are made to think about unique characteristics of an individual (Macrae, Bodenhausen, \& Milne, 1998; Fiske \& Neuberg, 1990; and Monteith, 1993). Moreover, studies have shown people may inhibit the activation or application of a stereotype when it is viewed as being irrelevant such as in cases where individuating information about the target is available (Leyens, Yzerbyt, \& Shadron, 1992; Yzerbyt, Schadron, Leyens, \& 
Rocher, 1994). It is hypothesized that when the participants listen to the "unique" harms that the burglary and aggravated assault have caused, the participants will think about the victim as a unique human being and less as a member of a specific racial category. It is conjectured that participants will draw upon, the information provided by the study materials, specifically the victim impact statement/harm statement (when available) when determining a sanction for the offender rather than relying upon stereotypes or heuristics. Reliance of on individuating information contained the harm statement portion of the victim impact statement will attenuate the influence of race on sentencing choice, and thus reduce sentencing disparity.

Furthermore, it is anticipated that there will be a main effect for the judge's instructions variable. Presumably, harsher penalties will be given to a defendant when the jurors (participants) are explicitly instructed to weigh the VIS with other aggravating and mitigating factors. These instructions function to emphasize the goal of selecting a sentence based, at least in part on the victim impact statement. Research has shown that demands for accuracy may reduce the reliance on stereotypes and encourage people to increase their complexity of thought which may lead to the devaluation of stereotypes and facilitate the integration of the individuating information (Kruglanski \& Webster, 1996: In Kunda \& Spencer, 2003). Research performed by Platania and Berman (2006) show that judges' instructions unique, characteristics of the victim and the unique details and detriments surrounding their case will further increase the likelihood that jurors will think of minority victims as unique individuals rather than as typical members of a racial stereotype. Thus, judges' instructions that focus jurors' attention on weighing the VIS 
with the other aggravating and mitigating factors will further decrease the sentencing disparity between Caucasian victims and African American victims.

Figure 1: Sentencing Outcomes Based on Manipulations

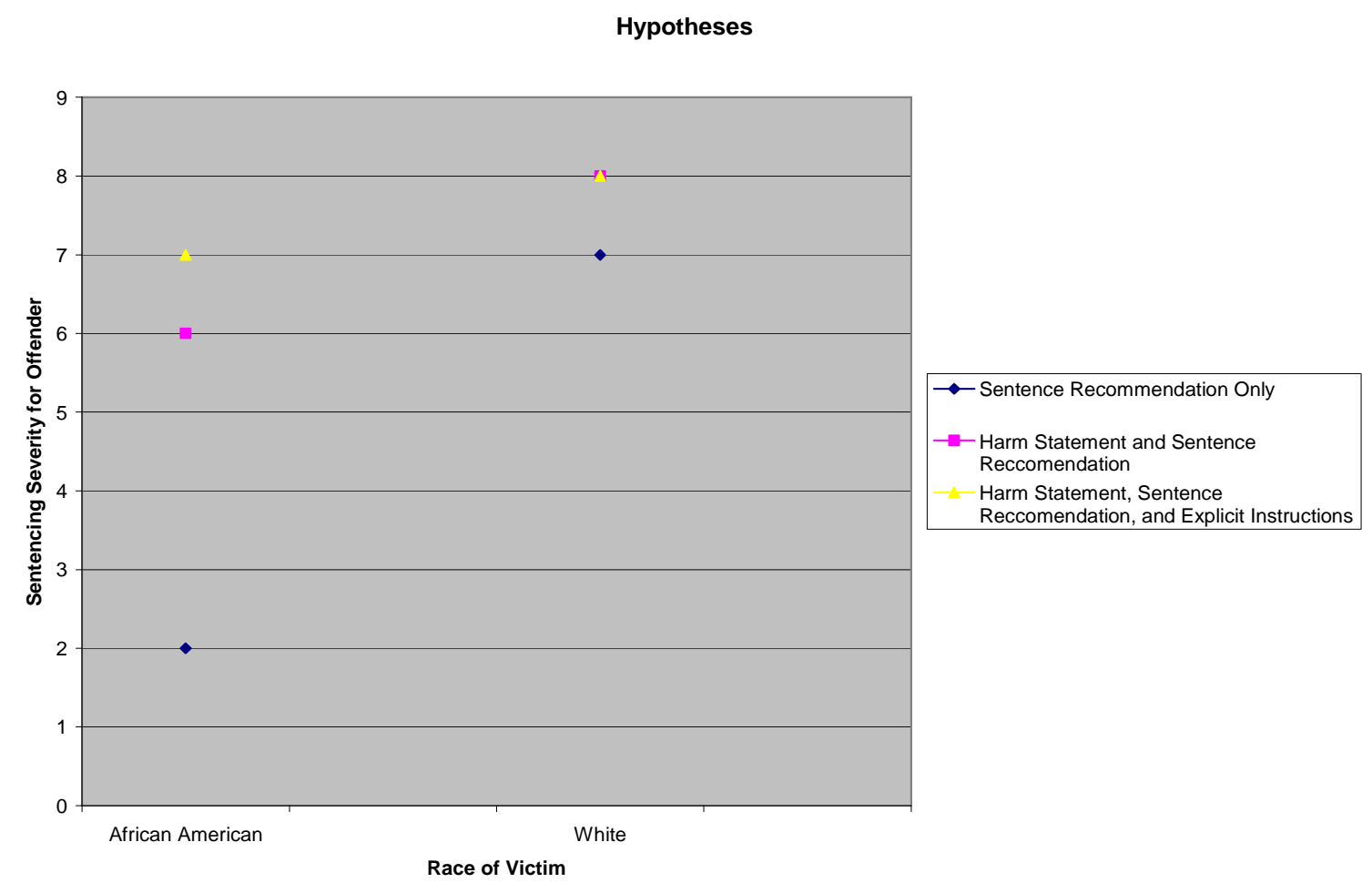

The main thrust of the study is to see if any of these factors, and more likely a combination of factors, studied will help to bridge the disparity in sentencing between Caucasian victims and African-American victims. Hopefully, the results will show a greater equality in sentencing (between Caucasians and African Americans) when the participants receive the content rich VIS (harm statement and sentence recommendation) as well as the guidelines explicitly stating that they (the participants) should consider and weigh the harms in the VIS with the other information proffered in the sentencing 
hearing. These hypotheses assume that the participant believes that the victim has reacted justifiably to the crime.

GOALS OF SENTENCING

It is hypothesized that participants who select probation with a combination of community-based sanctions will be more likely to endorse sentencing goals that reflect restorative ideals (e.g. restore the harm done to the victim and community, or rehabilitate the offender) than those who select a prison term. Conversely, those who select prison will be more likely to select retributive justice sanctions (e.g. the offender is punished in proportion to his crime) or individual or general deterrence than those who select either one of the probation sanctions.

\section{METHOD}

The design of the study is a 2 (Race of victim: African American, Caucasian) x 2 (Content of Victim Impact Statement (VIS): Sentence Recommendation Only, Both Sentence Recommendation and Harm Statement) x 2 (Jury Guidelines for VIS: No guidance, Explicit instructions to weigh the harm statement with other aggravating and mitigating factors) between subjects factorial design. In addition, a pilot study was used to select photographs to be used in the manipulations used in the primary study, as well as examine the perceived severity of the recommended sentences.

\section{PILOT STUDY}

Participants were drawn from Loyola University Chicago subject pool. Twenty-one undergraduates completed the pilot study. The sample was composed of 20 females and one male participant. 
The participants were presented with an informed consent form. Once the form was completed, a trained experimenter read the instructions and asked if the participants had any questions about their task. If there were not any questions the experimenter started the study.

The first task of the participants was to rate a series of photographs that could potentially be selected for the race manipulation on the primary study. The photographs consisted of 20 African-American and 10 Caucasian middle-aged males that would be used as the offender and victims in the crime scenario. The participants were asked to rate each man in the photograph on a seven point scale for attractiveness and strength. Furthermore, participants were instructed to indicate the race of the individual in the photograph as well as their socio-economic status the choices were: below poverty (1), lower middle class (2), middle class (3) and upper middle class (4). Photographs with similar attractiveness, strength and socio-economic statuses were selected in order to minimize confounds on these dimensions.

In the second phase of the pilot study participants were asked to equate several variations of community based penalties (straight-probation and intensive supervision probation) with a prison sentence (in months). Participants were provided with an explanation of each sanction. The purpose of this was to attempt to establish the sample populations, in this case college students, perception of severity of each of the 36 community-based punishments (one of two types of probation as well as a combination of restitution, community service and court-ordered treatment). 


\section{PRIMARY STUDY}

PARTICIPANTS AND SAMPLING

A total of 191 students enrolled in introductory psychology completed the study for partial course credit. The majority of the sample participants were female (138: 72.3\%). The racial ethnic composition of the sample was Caucasian (131: 68.6\%), Asian/Pacific Islander (23: 12\%), Hispanic/Latino (19: 9.9\%), African-American (7: $3.7 \%$ ), and 10 participants identified themselves as being in an Other racial category $(5.2 \%)$. One participant did not provide his or her race. The average age of the participants was 18.53 years.

Data for analyses was based on 176 participants. Fifteen participants were excluded from analysis based on extremely incomplete questionnaires and/or blatant disregard for the task (e.g. extremely inconsistent response patterns). The composition of this sample was very similar to that reported in the total sample: $(125: 71 \%)$ female, $(122$ : 69.3\%) Caucasian, (20: 11.4\%) Asian/Pacific Islander, (17: 9.7\%) Hispanic/Latino, (7: 4\%) African-American, and (9: 5.1\%) Other.

\section{$\underline{\text { MATERIALS }}$}

\section{STATEMENT OF FACTS AND VICTIM IMPACT STATEMENT}

The Statement of Facts in this case describes the defendant as a 36 year old African American male. The defendant begins his evening drinking at a local tavern and then gets in a verbal exchange about a debt that the defendant owes another patron. On his way home the offender stops at a house that he believes to be empty, breaks in, and 
steals items from the house. During the process, the offender wakes up the victim who was ill. The victim gets out of bed and grabs the phone, but it not able to dial 911, because the offender takes the phone out of his hand and hits the victim in the head with enough force to render him unconscious. The offender then leaves the victim's home.

The offender is an African-American male in all conditions. The case varies the race of the victim and the victim's family is described as being either African-American, or Caucasian-American. Pictures of the defendant and the victim are provided in each condition in order to strengthen the race manipulation. Based on the pilot study, the African-American victim, Caucasian victim, and the offender had similar ratings on attractiveness, strength and socio- economic status. The offender has a mean attractiveness, strength, and socio-economic status ratings of 2.05, 5.19, and 2.19 (lower middle class) respectively. The African-American victim had an attractiveness rating of 1.95 , and a strength rating of 5.05, and was also viewed as lower-middle class on average (2.48). Similarly, the Caucasian victim had an attractiveness rating of 2.17, and strength and socio-economic ratings of 4.33 , and 2.67 (lower middle class to middle class) respectively.

Additionally, the content of the victim impact statement (VIS) was varied. Participants were randomly assigned to read a victim impact statement (VIS) that consisted of only a sentencing recommendation where the victim asked that the defendant be given the maximum penalty by law or a VIS that consisted of both a sentence recommendation and a statement of harm. The harm statement describes the physical, financial and psychological harm that the victim incurred as a result of the defendant's 
crime. The victim states that the damages of the crime go beyond physical pain and loss of property. He describes that the crime resulted in depression, marital discord and decreased feeling of security in addition to thousands of dollars in medical bills and intense physical pain and suffering that came as result of the attack. Furthermore, the attack occurred around the holidays and ruined his family's holiday as gifts had to be returned due to the financial burden and Christmas dinner consisted of hospital food. The same sentence recommendation was used in both the sentence recommendation only and sentence recommendation and harm statement conditions. The sentencing recommendation states that due to the physical, psychological, and financial damages the defendant should receive a very severe sentence and be required to work to pay the victim back for all the damage he has done. It is of the utmost importance to hold these manipulations constant in order to avoid confounds.

\section{DEFENDANT BIOGRAPHY INFORMATION}

All the participants were provided with biographical information about the defendant, the biographical information was held constant across all conditions. The offender was described as a 36 year old African American male who is divorced and has two children. The offender held a job as a store manager for 15 years, but was fired a year prior to his offense due to tardiness and erratic behavior which were attributed to increasing problems with alcohol consumption. The offender now works part-time as a store clerk, and has not paid child support since losing his store manager position. He is divorced and is not currently dating. The offender has prior arrests. 
JUDGE'S INSTRUCTIONS

All participants received highly comprehensible set of judge's instructions for sentencing. The judge's instructions varied on instructions as to how the VIS should be interpreted or used. In the control condition participants received no specific guidelines as to how VIS should be interpreted, which was adapted from Ark. Model of Criminal Instructions 2d 9102 \& Va. Model of Jury Instructions: Crim. No. P44-100. Participants received a statement that the offender has been convicted of two felonies residential burglary and aggravated battery. In the other conditions, participants received the same statement as well as instructions that the victim impact statement should be used as part of the information to determine the amount of harm the offender caused to society and the victim as they consider the appropriate sanction for this offender, which was adapted from Cargyle vs. State, 1995.

The Judge's Instructions informed participants to impose a sentence on the offender that they found appropriate. The instruction did not provide the standard range of appropriate sentences, but informed them of their disciplinary choices (prison, probation, restitution and various combinations etc.).

\section{QUESTIONNAIRES}

The first questionnaire was constructed to capture each participant's sentencing recommendation. The participants were asked to select a punishment from a list of choices. Participants could select different combinations of community based (either straight probation or intensive supervision probation) sentences or they could choose a prison term. 
Straight probation was described as a period of four years where the offender lives in his residence and must meet with a probation officer at least twice a month. Additionally, the probation officer will be an unannounced bi-monthly visit to the offender's home. The offender is refraining from drug and alcohol consumption and is tested by his probation officer. Other sanctions could be included, such as community service, restitution, and court-mandated treatment.

Intensive supervision treatment was described as the offender living on his own, but under more surveillance from his probation officer (strict curfews, more frequent office and home visits). The amount of surveillance decreases over time (three phases during the first year). Like straight probation the offender is tested for drugs and alcohol. All other conditions of straight probation are the same after one year. Like straight probation, other sanctions could be included to intensive supervision probation like community service, restitution, and court-mandated treatment.

Prison was described as: "the offender lives in a prison where there is rarely treatment available. The offender will work for extremely low-wages while in prison. Once the offender is released from prison he will likely find it difficult to obtain and maintain employment."

Participants were then asked to indicate how severe they thought their penalty was and how confident they were in their selection. Other questions asked participants to rate how much emotional pain the burglary and attack caused the victim's family; how much financial hardship the victim and his family incurred as a result of the crime; and how severe the physical attack was. Another question requested that participants describe the 
case in their own words. This was administered before the manipulation checks, and assesses how many participants spontaneously mentioned race in their written descriptions of the case.

The second part of the questionnaire asked participants to provide demographic information (sex, race, age etc.) about themselves, control variables. These questions provided information on the characteristics of the sample. Furthermore, this information may be used at a later date for further analyses.

The second part of the questionnaire also included a series of manipulation checks, for each of the independent variables. One question asked participants to state the race of the victim. Another asked participants to recall the race of the defendant. Another question asked participants to indicate whether or not the victim made a sentencing recommendation, and if so to state that recommendation. Another question instructed participants to provide a brief description of the harm statement given by the victim. In order to gauge whether the judge's instructions were understood participants were asked to provide a brief description of the judge's instructions in their own words. $\underline{\text { PROCEDURE }}$

All data were collected via Opinio computer software through Loyola University Chicago. Participants were randomly assigned to one of the eight conditions. A random number generation was developed by Loyola's technical service team to ensure that participants were randomly assigned to one of eight conditions and that the eight conditions were counterbalanced. 
Participants signed up for the experiment using Experimetrix software and were sent a link to the Opinio survey. The students completed the survey from a computer of their choice and at their convenience, once they received the link to the survey. Once participants opened the link a brief description of the survey appeared and then the participants were directed to the Informed Consent Form where participants were given a description of the study and credit they would receive for completing the study. The brief description of the study was that each participant would be asked to read a statement of facts about a crime, a brief biography of the defendant's life and past crimes, a victim impact statement and judge's instructions. Once this was completed the participant would be asked to fill out two questionnaires. One questionnaire would ask the participants to choose a punishment for the crime as well as some other questions related to the crime and to the punishment they selected. The second questionnaire would ask the participants to answer some questions about themselves. The participants were told that this study would take no more than an hour to complete. If the participant chose to participate in the study, the random number generator selected the condition and automatically selected the materials and questionnaire associated with that condition, and the respondent began reading the material.

If the participant agreed to participate, they all first (regardless of condition) received the Statement of Facts followed by the Defendant Biography. Once they completed reading Defendant Biography the participants received the condition appropriate version of Victim Impact Statement (recommendation only or recommendation and harm) with either a picture of a Caucasian or African-American 
victim depending on the condition. Once the VIS had been read, the participants read the condition specific version of the Judge's Instructions on how to use the VIS in making their sentencing decision.

Once the Judge's Instructions were read, the participants began filling out the first questionnaire that asks them to select a punishment. Once participants completed the first questionnaire they filled out the second questionnaire that contained the manipulation checks. Participants were not able to look at case materials as they were filling out either questionnaire.

Once participants finished the final questionnaire they read a debriefing statement that provided some additional information about the study as well contact information in case they had any lingering questions about the study. The debriefing statement did not provide information about the hypotheses being tested or the conditions of the study to avoid contamination in the study due to respondents talking to other potential respondents about the study. Participants were then thanked and logged out of Opinio.

\section{RESULTS}

\section{OVERVIEW OF FINDINGS}

The findings are organized around three questions: (1) What are the effects of the type VIS, judge's instructions, and the race of the victim on respondents' perceptions of the victim and the harm caused by the crime? (2) Do individuals who judge the victim as reacting appropriately (justifiably) to the crime differ in their perceptions and sentencing recommendations compared to individuals who believe the victim has overreacted to the 
crime? (3) How do these three manipulations affect the respondents' sentencing goals and recommended sentences? For each of these three main questions, I also examined how the respondents' gender and racial status (either Caucasian or minority) affected their interpretations of the information, sentencing goals, and recommended sentences. Before examining these questions, analyses are conducted to provide empirical support that manipulation of race of the victim, and the manipulation of the harm statement were successful.

\section{OVERVIEW OF ANALYSES}

For all analyses where the dependent measures were continuous, measured on a 1 to 7 rating scale, either a univariate analysis of variance (ANOVA) or a multivariate analysis of variance (MANOVA) were used. MANOVAs were used when there were correlations among the dependent measures. Multivariate analyses (MANOVA and ANOVA) tested all two way interactions, three way interactions of participants' minority status and the race of the victim with either victim impact statement or judge's instruction, and all three way interactions with whether the participant judged the victim as overreacting to the crime. The variable of whether the victim was judged as overreacting was incorporated into all analyses as it was an important inference that may affect participants' reliance on the victim's impact statement. For nominal dichotomous outcomes, Chi-Square analyses were initially conducted. Logistic regressions were then used to assess the unique effects of the manipulations (race, harm, and instructions), as well as the participants' gender and racial status (whether the participant is a minority or not). 


\section{MANIPULATION CHECKS}

\section{$R A C E$}

A chi-square analysis conducted to evaluate the race manipulation showed that $95.7 \%$ of the individuals presented with a Caucasian victim correctly labeled the person as Caucasian whereas only $73.2 \%$ of participants presented with the African-American victim correctly labeled the person as African-American, $\chi^{2}(2)=31.33, \underline{p}<$ .001. The $26.8 \%$ of individuals who mistakenly stated that the victim was Caucasian when presented with a African-American victim may have used their stereotype information to recall the race of the victim.

\section{HARM-STATMENT}

In order to evaluate whether or not the manipulation for harm statement was effective, respondents answered the question using a seven point scale $(1=$ Mild to $7=$ Severe): "How would you rate the emotional harm the victim experienced from this crime?" The statement of facts did not contain any information about emotional harm of the victim; thus, the unique information manipulated in the victim's impact statement was about their emotional harm.

The ANOVA results revealed that participants that received the harm statement and sentence recommendation rated the emotional harm sustained by the victim as being significantly more serious $(M=5.3)$ than participants who received the sentence recommendation only $(\mathrm{SRO})(M=4.4) ; F(1,171)=8.99, \underline{p}<.003$. These results suggest the harm manipulation successfully changed respondents' perceptions of the seriousness of the victim's emotional harm. 
An additional question was used to assess their perceptions of the victim's reaction to the crime and their interpretation of the victim's impact statement. Initially, an ANOVA that included all manipulations, gender, race of respondent was conducted. Only a main effect for type of victim impact statement was significant. Those with the harm statement were more likely to believe that the victim over-reacted to the crime ("The victim over-reacted to the crime") $(M=3.455)$ than those with the SRO $(M=2.818), F(1,163)=7.72, \underline{p}<.023$.

Original hypotheses were based on the assumption that respondents would perceive the victim as having a normal and justifiable reaction to the crime. The main effect of victim impact statement on respondents' perceptions of the victim indicates that the elaborate statement about emotional harm changed the view of the victim as overreacting and having a prior mental condition. To test whether views of the victim's affected the importance given to the victim's impact statement and judge's instructions in deciding sanctions for the offender, a dichotomous measure was created. The overreaction group was defined as participants who responded with a 4 or higher to the victim over-reaction item, and they comprised (39.1\%) of the total sample. The remaining $60.9 \%$ were defined as seeing the victim's reaction as justified.

To assess whether the victim impact statement affected respondents' perceptions of whether the victim overreacted, a logistic regression that controlled for all of the manipulations and the participants' gender and racial status was conducted. Only one effect was significant. Participants who received the victim impact statement with the detailed description of emotional harm and sentencing recommendation were 
significantly more likely to judge the victim as overreacting to the crime than were participants who read the victim impact statement that contained only the sentence recommendation, unstandardized coefficient $=.88$, odds ratio $=2.40, \underline{p}<.004$.

These analyses show that the victim's description of their emotional harm increased the perceived seriousness of the harm, but some respondents felt that the victim had an exaggerated emotional reaction to the crime that was not completely warranted. Subsequent analyses examine how this perception affects sentencing recommendations and interacts with the manipulations.

HOW MANIPULATIONS AFFECTED THE PERCEPTIONS OF THE VICTIM

ANOVAs were conducted on respondents' ratings of the victim. Overall, the participants in the VIS condition were more likely to say that the victim had more emotional problems (experience more guilt, had a pre-existing mental condition, and over-reacted to the crime) than those in the sentence recommendation condition (SRO).

Participants in VIS harm statement and sentence recommendation conditions were more likely to endorse that the victim has more guilt ("The victim has guilt over being the victim of a crime") $(M=4.19)$ than participants that received a sentence recommendation only $(\mathrm{SRO})(M=3.27) ; F(1,163)=7.715, \underline{p}<.006$. Again, participants who received both a harm statement and sentence recommendation were significantly more likely to believe that the victim had a pre-existing mental condition ("The victim had a preexisting mental condition") $(M=3.413)$ than SRO participants $(M=2.54) ; F(1,164)=$ $8.90, \underline{p}<.003$. 


\section{EFFECTS ON SENTENCING RECOMMENDATIONS}

Few studies have provided respondents with the flexibility to create a sentence using a variety of community-based sanctions such as community service, treatment, restitution, and jail time. Moreover, most studies have not given respondents the option of choosing intensive supervision probation. Thus, one contribution that has practical implications is the type of sentences respondents preferred overall. Overall, the majority of respondents (64.4\%) preferred intensive supervision probation, $22.5 \%$ recommended prison, and $13.1 \%$ recommended straight probation. To fully assess respondents' sentencing preferences, several measures of sentencing severity were created. Given the small percentage of respondents who chose standard probation, a dichotomous measure of whether prison was recommended or not was created. In addition, whether respondents chose any form of incarceration (prison or jail time) was created, and $58.1 \%$ chose to incarcerate the offender. To obtain a more sensitive measure of sentencing severity, the recommended number of years incarcerated was also analyzed. For respondents who chose a probation sentence with no time in the county jail, incarceration time was coded as zero years. Almost half (45.9\%) of respondents who chose a probation sentence also recommended between 1 to 10 months in jail. For the measure of number of years incarcerated, months in jail was converted to a proportion of one year. The vast majority of respondents who recommended probation combined the probation sentence with a term of community service (96.6\%) and $88.1 \%$ chose to impose restitution. Therefore, 
I analyzed the dollar amount of restitution and the hours of community service, and on these measures a zero was coded for participants who recommended probation but did not select restitution or community service.

RACE OF VICTIM AND SENTENCING RECOMMENDATION

Contrary to my hypothesis, no significant main effect for race of victim was found for sentencing severity, $\chi^{2}(2)=.091, \underline{p}<.955$.

Table 1: Percentage of Sentencing Choices by Race Manipulation

\begin{tabular}{cccc}
\hline & Straight Probation & Intensive Probation & Prison \\
\cline { 2 - 4 } African-American & $13.4 \%$ & $63.4 \%$ & $23.2 \%$ \\
Caucasian & $13.8 \%$ & $64.9 \%$ & $21.3 \%$ \\
\hline
\end{tabular}

In addition to simply looking at sentencing recommendations as an indicator of sentencing severity, whether or not the offender was sentenced to incarceration was also examined. In this case incarceration included those participants that chose a prison sentence and those participants who chose a probation sentence that included jail time as a sanction. Again, race of the victim was not found to have any significant effects on sentencing severity, $\chi^{2}(1)=.000, \underline{p}<.560$

Table 2: Percentage of Participants Selecting Incarceration by Race

\begin{tabular}{|c|c|c|}
\hline & Imposed Prison or Jail Time & No Prison or Jail Time \\
\hline African-American Victim & $58.5 \%$ & $41.5 \%$ \\
\hline Caucasian Victim & $58.5 \%$ & $41.5 \%$ \\
\hline
\end{tabular}


These results, contrary to my hypothesis, show that participants did not assign more severe penalties to the offender when he perpetrated against a Caucasian victim. In fact, from percentages displayed in the table above, one can see that the incarceration percentages are equal for the victims of both races.

VICTIM IMPACT STATEMENT AND SENTENCING RECOMMENDATIONS

As hypothesized, a main effect for type of victim impact statement was significant, $\chi^{2}(2)=5.21$, one-tailed $\underline{2}<.035$. Participants who received the harm statement and sentencing recommendation were more likely to sentence the offender to prison (27.9\%) than participant who read the sentencing recommendation only (16.7\%). Table 3: Sentencing Selections Based on VIS and Victim Perception

\begin{tabular}{|c|c|c|}
\hline & Probation & Prison \\
\hline $\begin{array}{l}\text { Sentence Recommendation } \\
\text { Only }\end{array}$ & $83.3 \%$ & $16.7 \%$ \\
\hline Victim Reacted Justifiably & $79.0 \%$ & $21.0 \%$ \\
\hline Victim Overreacted & $92.6 \%$ & $7.4 \%$ \\
\hline Harm Statement and SR & $72.1 \%$ & $27.9 \%$ \\
\hline Victim Reacted Justifiably & $65.9 \%$ & $34.1 \%$ \\
\hline Victim Overreacted & $78.0 \%$ & $22.0 \%$ \\
\hline
\end{tabular}

Additionally, as hypothesized, a marginally significant effect for type of victim impact statement emerged when severity was measured by whether the offender was sentenced to some type of incarceration, $\chi^{2}(1)=2.84$, one tailed $\underline{p}<.076$. Participants were somewhat more likely to impose incarceration $(63.8 \%)$ when they received that harm 
statement and sentence recommendation than when they received the harm statement only $(52.6 \%)$.

A non-significant trend emerged for participants who believed that the victim's reactions to the crime were justified. Participants in the harm statement and sentence recommendation condition tended toward imposing prison on the offender (34.1\%) than those in the sentence recommendation only condition $(21 \%) ; \chi^{2}(1)=2.28$, one tailed $\underline{<}<$ .100. Those participants who believed the victim had overreacted showed a similar trend. Those in the harm statement and sentence recommendation condition imposed prison $(22 \%)$ than those in the sentence recommendation only condition $(7.4 \%) ; \chi^{2}(1)=2.54$, one tailed $\underline{<}<.102$.

Participants who believed that the victim overreacted to the crime were significantly more likely to impose some type of incarceration (prison or jail time) in the harm statement and sentence recommendation condition (58.5\%) than those in the sentence recommendation only condition $(33.3 \%) ; \chi^{2}(1)=4.14$, one tailed $\underline{2}<.036$. For those who believed the victim's reactions were justified there were no significant differences in incarceration between the type of VIS conditions; $\chi^{2}(1)=.951$, one tailed $\underline{p}<.222$.

\section{JUDGE'S INSTRUCTIONS AND SENTENCING RECOMMENDATIONS}

The type of judges instructions that the participant received did not significantly (on their own) impact the type of sentence the participant selected, $\chi^{2}(2)=3.92$, onetailed $\underline{p}<.07$. Furthermore, judge's instructions did not play a significant role (on their own) in whether or not incarceration was selected, $\chi^{2}(1)=.141, \underline{p}<.410$. Subsequent 
analyses were conducted to explore the differences in sentencing recommendations between those who believed that the victim over-reacted to the crime and those who believed that the victim's reactions to the crime were justified.

Furthermore, participants who believed that victim's reaction to the crime were justified were significantly more likely to sentence the offender to prison when they received the judge's instructions that explicitly instructed participants to weigh the aggravating and mitigating evidence (46.2\%) than when they received the non-explicit (no VIS instructions (16.7\%), Fischer Exact one-tailed, $\underline{p}<.03$. Conversely, for those who believed that victim over-reacted to the crime and received the explicit judge's instructions were less likely to sentence the offender to prison $(6.7 \%)$ compared to those who received the non-explicit judge's instructions (23.7\%), Fischer Exact one-tailed, $\underline{p}<$ .056 .

LOGISTIC REGRESSION: MANIPULATIONS AND CONTROL EFFECTS ON SENTENCING RECOMMENDATIONS

Two logistic regressions were performed to determine the factors (controls \& manipulations) that contributed to sentencing selection (whether probation or prison was selected). For those who believed that victim's reaction to the crime was normal (or justifiable), the first column of results in Table 6 presents the significant interaction effect between VIS and Judge's Instructions. When victims were perceived as having a normal reaction, participants were significantly more likely to recommend prison when they read the VIS that included the harm statement and received explicit judges 
instructions on how to interpret and use victim impact information than in all other conditions, odds ratio $=3.39$, one-tailed $\underline{p}<.049$.

The second column of results in Table 5 presents the results for when victims were seen as over-reacting to the crime. For those participants who believed that the victim over-reacted to the crime, there was a main effect for type of VIS. Individuals who believed that the victim over-reacted were significantly less likely to recommend prison when they received the VIS with the explicit harm statement than when they received a VIS with only a sentence recommendation. Similarly, participants were significantly less likely to assign prison to offenders when they received the VIS with explicit harm statement and the explicit judge's instructions for interpreting that information.

Table 4: Logistic Regression Predicting Whether Prison Was Recommended

\begin{tabular}{lll}
\hline Variables & $\begin{array}{l}\text { Model testing } \\
\text { interaction with } \\
\text { victim seen as } \\
\text { justifiable } \\
\text { reaction }\end{array}$ & $\begin{array}{l}\text { Model testing } \\
\text { interaction with } \\
\text { victim seen as } \\
\text { overreacting }\end{array}$ \\
\hline Controls & -.08 & \\
Female Participant & $(.92)$ & -.13 \\
Minority Participant & -.08 & $(.88)$ \\
Victim Perceived as Overreacting & $(.92)$ & -.22 \\
& -.33 & $(.80)$ \\
Manipulations & $(.72)$ & -.32 \\
Victim Impact Statement (VIS) is & & $(.73)$ \\
Harm and Recommendation (HR) & .30 & \\
African-American Victim & $(1.35)$ & $.94^{2}$ \\
Explicit Judge's Instructions & .13 & $(2.57)$ \\
& $(1.14)$ & .11 \\
& -.32 & $(1.12)$ \\
& $(.73)$ & $(1.60)$
\end{tabular}


Interaction effect:

Explicit Judges Instruction combined with

HR VIS and victim is seen as normal

Explicit Judge's Instruction combine with HR

VIS and victim is seen as overreacting

Model Chi-Square

DF

p-value

Nagelkerke R-Square
$1.22^{1}$

$\begin{array}{ll} & -2.17^{3} \\ & (.114) \\ 10.09 & 12.20 \\ 7 & 7 \\ .18 & .09 \\ .086 & .104\end{array}$

Note: Top number in a row is the unstandardized logistic coefficient and the number in parentheses is the odds ratio. ${ }^{1}$ one-tailed p-value $<.049{ }^{2}{ }^{2}$ one-tailed p-value $<.008$.

${ }^{3}$ one-tailed $p$-value $<.03$.

Based on chi-square analyses, type of VIS, Race of the victim and type of judge's instructions did not significantly affect whether or not the participants selected (or did not select) various community-based sanctions (restitution, community service, and jail time).

\section{$\underline{\text { RESTITUTION }}$}

An ANOVA was used to assess the effects of the independent variables, as well perceptions about whether the victim over-reacted, as well as characteristics of the participant (gender and minority status), on amount of restitution recommended. The results revealed a significant main effect for Type of victim impact statement $F(1,110)=$ 9.134, $\underline{p}<.003$. A follow-up test confirmed that the results were in the predicted direction. Participants who received the harm statement and sentence recommendation imposed a significantly greater amount of restitution $(M=\$ 5262.26)$ than those who received the sentence recommendation only $(M=\$ 3004.05), t(116)=-3.31, \underline{p}<.001$. In order to account for the skewedness of this variable restitution amounts in excess of $\$ 10,000$ dollars were collapsed into the $\$ 10,000$ amount for the aforementioned analyses. 
A significant two-way interaction between the race of the victim and type of VIS emerged, $F(1,110)=4.64, \underline{p}<.033$. Follow-up analyses revealed that there was no difference in the amount of restitution participants imposed on the offender when the victim was Caucasian regardless of the type of VIS the participants read $t(68)=-1.26, \underline{p}$ $<$.211. However, when the victim was African-American participants who read the VIS that included the harm statement assigned significantly more restitution $(M=\$ 6294.63)$ than those who read the harm statement only $(M=\$ 2730.56), t(46)=-3.69, \underline{p}<.001$. Table 5: Mean Dollar Amounts Assigned to Offender Based on Manipulations

\begin{tabular}{ccc}
\hline & $\begin{array}{c}\text { Sentence Recommendation } \\
\text { Only }\end{array}$ & $\begin{array}{c}\text { Harm Statement and } \\
\text { Sentence Recommendation }\end{array}$ \\
\cline { 2 - 3 } African-American & $\$ 2,730.56$ & $\$ 6,294.63$ \\
Caucasian & $\$ 3,263.16$ & $\$ 4,465.86$ \\
\hline
\end{tabular}

\section{Community Service}

As with amount of restitution discussed above, an ANOVA was used to assess the effects of the independent variables, as well perceptions about whether the victim overreacted, as well as characteristics of the participant (gender and minority status), on amount of community service assigned.

In order to ensure statistical integrity, hours of community service exceeding 500 were collapsed in the 500 hour category in order to decrease the skewedness of the variable. Only type of VIS was found to influence the amount of hours of community service that participants imposed on the offender, $F(1,111)=6.32, \underline{p}<.013$. However, contrary to the hypothesis, participants who read the sentence recommendation only 
assigned significantly more hours of community service $(M=195.55)$ than participants in the harm statement and sentence recommendation condition $(M=149.76)$. It is not entirely clear why participants would impose fewer hours of community service in this situation. Furthermore, no interaction effects emerged, that could shed light on this result.

\section{$\underline{\text { JAIL TIME }}$}

An ANOVA was used to examine effects of the independent variables, as well perceptions about whether the victim over-reacted, as well as characteristics of the participant (gender and minority status), on the amount of jail time imposed. None of the independent variables was found to have a significant effect on the amount of jail time that participants imposed on the offender.

However, the participants' perceptions on the victim's reactions to the crime were found to have a marginal effect on the amount of jail time that participant's imposed on the offender $F(1,109)=3.77, \underline{p}<.055$. As would be expected, participants who believed that the victim's reactions to the crime were justified assigned more jail time (in months) to the offender $(M=2.61)$ than did participants who believed that the victim had overreacted to the crime $(M=1.80)$.

\section{GOALS OF SENTENCING}

The figure below depicts the breakdown of the top two goals of sentencing selected by the participants. The following analyses were based on whether any of the goals of sentencing were listed in the top two goals (i.e. repair harm or deterrence etc. was listed as one of the top two goals). 
Figure 2: Proportion of Top Goals for Sentencing

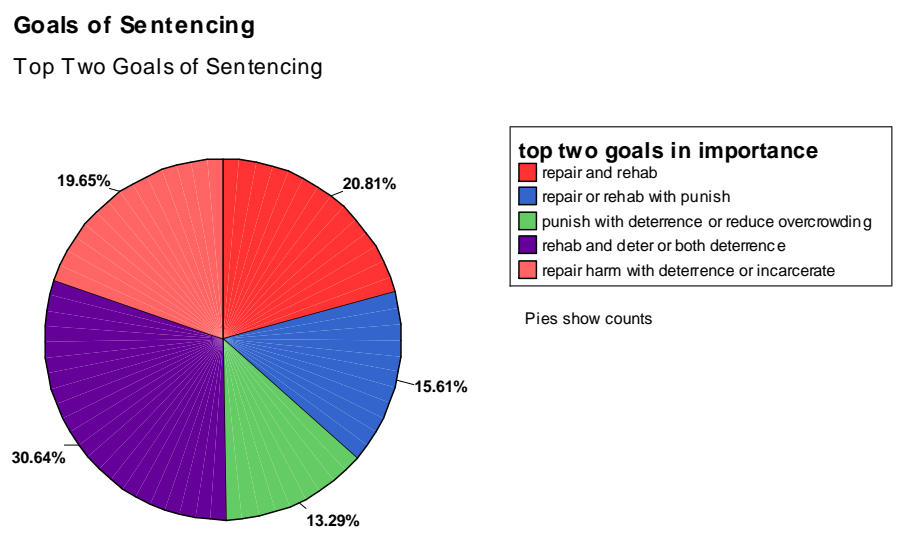

A layered chi-square analysis was performed to determine the relationship between sentencing goals and the victim impact manipulation. The results revealed that for participant's who believed the victim's reaction to the crime were justified, those received the harm statement and sentencing recommendation $(56.8 \%)$ were significantly more likely to indicate that restorative justice was among their top sentencing goals than when participant's who received the sentencing recommendation only (37.1\%), Fischer's Exact Test, $\underline{p}<.035$.

The results of a logistic regression provided further evidence for the aforementioned finding. Specifically, participants were more likely to select restorative justice goals when they received the harm statement and sentencing recommendation than when they received the sentence recommendation only; odds ratio $=2.71$, one-tailed $\underline{p}<.01$. In other words, participants in the harm statement and sentence recommendation condition were approximately two times more likely to select restorative justice (repair harm done) goal than those in the sentence recommendation only condition. 
Chi-square analyses were conducted to examine the relationship between the race of the victim and goals of sentencing. A significant effect of race was found. When the victim was African-American individual deterrence was rated as a more important goal of sentencing (54.0\%) than when the victim was Caucasian (30.4\%); Fisher's Exact onetailed, $\underline{p}<.011$.

Conversely, repairing harm done (restoration) selected as a top goal of sentencing when the victim was Caucasian (59.5\%) than when the victim was African-American (40.5\%), Fisher's Exact, one-tailed, $\underline{p}<.088$. This trend is accentuated when the victim was thought to overreact to the crime, restoration was considered more important for Caucasian victims (64.9\%) than when the victim was African-American (35.5\%); Fisher's Exact one-tailed, $\underline{p}<.015$.

\section{GOALS OF SENTENCING: LOGISTIC REGRESSION}

Logistic regression controlled for the type of VIS, type of judge's instructions, over-reaction, gender, and participant's race. Results revealed that participants were more likely to rate "repair the harm done" (restoration) as a top goal when the victim was Caucasian than when the victim was African-American; odds ratio $=1.64$, one-tailed $\underline{p}<$ .054. Thus suggesting that restoration of the harm done was seen as more important when the victim was Caucasian than when the victim was African-American. Conversely, individual deterrence was seen as more important when the victim was African-American than when the victim was Caucasian.

No other manipulations, participant characteristics, or combination of manipulation and participant characteristics were found to have a significant effect on the 
goals of sentencing. No other factors were found to contribute to any of the other (possible) goals of sentencing. This assertion was confirmed through both chi-square analyses and logistic regressions.

\section{DISCUSSION}

Contrary to my original hypothesis no differences in sentencing severity were found based on the race of the victim. The only differences between races were found in the area of restitution allocated where African-American victims were awarded more money than Caucasian victims. However, this finding only occurred when participants believed that the victim overreacted to the crime. In this case, African-American victims were awarded more money than Caucasian. This is a curious finding since it runs counter to the stereotype.

Race of the victim did play a role in the goals of sentencing that participants selected. The analyses suggest that participants chose restorative goals for sentencing when the victim was Caucasian and more deterrence goals when the victim was AfricanAmerican. The reason for this is not totally clear, especially considering that AfricanAmerican's and Caucasians were awarded the same amount of restitution (except in cases where the victim was thought to overreact where African-Americans were actually awarded more money). The offender was sentenced to equal amounts of the community service and jail time, regardless of the victim's race. It could be that participants believe that Caucasians are generally wealthier than African-Americans and thus do not require as much money to restore the amount of harm done. However, this explanation does not account for the fact that the harm statement included a dollar amount of medical debt that 
the victim incurred as a result of the attack. This dollar amount did not vary across race of the victim.

This finding also fits with the group value model (Tyler, Degoey, \& Smith, 1996). Caucasians are viewed as valuable members of society, thus it is important to rehabilitate and integrate those who victimize them back into society. Conversely, according to this model it is not as important to restore and reintegrate offenders who victimize members of an out-group (i.e. African-Americans), because these outgroup members are not seen as being as important as in-group (Caucasian) members. It does not matter, in some sense, that the Caucasian victim overreacted because he is still a member of the in-group whose safety is of maximum importance.

The type of judge's instructions, on its own, did not have a significant impact on sentencing severity or selection of community-based sanctions. It seems that on their own judge's instructions do not have an impact on the participant's beliefs or on the sanctions they impose. However, as hypothesized, the judge's instruction did play role in sentencing severity when paired with the VIS that included an explicit statement of harm.

As projected, type of victim impact statement did have a significant impact on sentencing severity. Those participants who read the victim impact statement that included the harm statement were more likely to sentence the offender to prison than when they read the sentence recommendation only. Furthermore, the results of the logistic regression showed that compared to all other conditions, participants who read the victim impact statement that included the harm statements and received the judge's instructions that provided explicit instructions for how to interpret them were 
significantly more likely to sentence the offender to prison (when they believe that the victim had acted appropriately to the crime).

Additionally, participants awarded greater dollar amounts of restitution to the victim when they read the VIS with the harm statement than when they read the sentencing recommendation only. However type of VIS had no impact on the amount other community based sanctions, that is participants did not assign more hours of community service, jail time, or weeks in treatment to the offender when they received the harm statement. On the surface this seems a bit peculiar, however it may be because past research has shown that restorative sanctions are not given in proportion of the crime, but as a means to restore the harm done to the victim and to the community. It is possible that participants did not select higher levels of community service or jail time, because they believed that the offender's crime did not directly impact the community, since the VIS did not include any information about how the offender's crime (actions) impacted the community (e.g. increased police patrolling of the area, the fear neighbors experienced as a result of his crime). If this information had been included we might have observed an increase in hours of community service and/ or jail time. In other words, restitution was the only community-based sanction that directly restored the harm done to the victim.

\section{LIMITATIONS}

I realize that there are several limitations of the study. In the following pages I will address each of these limitations and the impact that these limitations could have on 
the results of the study. Some of these limitations seem to be more detrimental than others.

Curiously, or perhaps not so curiously, over $25 \%$ of the participants assigned to conditions where the offender was African-American misidentified the victim as Caucasian. However, less than $5 \%$ of those who were in conditions with the Caucasian victim incorrectly answered that the victim was African-American. There are two possible explanations for this, (1) the picture of the African-American victim was somewhat ambiguous and the picture of the Caucasian victim was clear; (2) the participants used their stereotypes of who victim's are (i.e. Caucasian) and who offenders are (i.e. African-American). While it is true that the African-American "victim" is lighter-skinned than the African-American "offender", it does not seem likely that the victim's physical characteristics or the picture quality for that manner were driving this phenomenon. The photographs were pilot-tested and no one misidentified the race of the person in the photo for either of the "victims" that were used in the study. From this, it seems most likely that participants used their stereotypes to fill in the race of the victim. This may have had an effect on the results of race effects since it was a sizable portion of the participant pool that made this mistake.

One way to improve upon the photo manipulations would be to use software that transforms the same picture to different races this way we could be sure that there were no confounds of attractiveness, strength etc. Moreover, with this type of software the skin color of the African-American offender and victim could be equated, thus eliminating this confound. Unfortunately, this type of software was not available for the 
current project. Additionally it should be addressed that nearly $40 \%$ of the sample believed that the victim had overreacted to the crime. This is important to readdress since the hypotheses were contingent on the assumption that the victim reacted justifiably to the crime. It is possible that the participants believed that victim overreacted because of their stereotypes about men. The VIS included explicit statements of emotional harm that could be considered "uncharacteristic" of men. In retrospect, the VIS should have been pilot tested to see how believable and justifiable the victim's reactions were for a male victim. Certainly, one way this study could be improved would be to generate multiple victim impact statements and have people rate them on how believable and sympathetic the victim appears.

As with many other experiments done in psychology the sampling of undergraduates is a possible limitation of the study. First it is possible that the typical 18 year old college student does not know as much about the criminal justice system and punishment as a typical 30 year old in a community sample. Second, and perhaps more importantly, the typical 18 year college freshman has a much more limited knowledge of financial constraints than the average adult in America. College students, for the most part, have not yet had to worry about working full-time to pay bills, rent/mortgage, and medical insurance. Furthermore, people in the first-year in college typically are not married or have had children. For these aforementioned reasons, assessments of the emotional and financial amount of harm done to the victim may be more difficult for college first-year students than for the "average" adult in a community sample. There is reason to believe that if this exact study had been given to a community sample that there 
may be been different and more consistent patterns of restitution awarded to the victim and community service and jail time imposed upon the offender than was found in the student sample.

One oversight of the study was that the manipulation checks did not include a question that asked participants' what they thought the purpose of the study was. There is a possibility that hypothesis guessing about stereotypes could have led participants (especially Caucasians who made up the majority of the participants in the study) to consciously avoid making stereotype consistent judgments to avoid looking prejudicial. It is a possibility that when Caucasian participants saw a photograph of the AfricanAmerican offender, they guessed (correctly) that this study was assessing stereotypes and prejudice even though it was a between-subjects design. However, given that the goals were in the expected directions, it is likely that many participants believed that the study was assessing preferences in moderately serious crimes. Furthermore, it is not particularly uncommon (or specific to this study) to not find race effects. There are many published studies, using both community and student samples where race effects do not emerge (need citations). Thus, failure to find race effects may not be an anomaly that can be attributed to highly salient demand characteristics.

In retrospect, one way this could have been avoided is if a photograph of a Caucasian offender had been used either in addition to or in place of the photograph of the African-American offender. This (in addition to a question assessing hypothesis guessing) would have made it easier to see if participants were modifying their responses to avoid looking bigoted. This would have given me an idea whether or not participants 
were aware of (one) the hypotheses and modifying their responses and perhaps (by using the photo of the Caucasian offender) seeing how much they were changing their responses. However, there is always the possibility that using any photograph may have "tipped" the participants off to the study's hypotheses.

One way to reduce the demand characteristics of the study would be to have presented the information as a video of the hearing. This format would make race less obvious since the attorneys, judges and other courtroom players race and ethnicities would also be presented, rather than simply the victim and offender manipulations. This methodology would increase the external validity of the study, since the depiction of the hearing would be closer to "reality" than written materials.

\section{$\underline{\text { FUTURE DIRECTIONS }}$}

In considering the limitations of the study I think it would be best to make the aforementioned changes to the study and re-run it with a student sample and community sample to pinpoint where the differences are between student and community samples. It is likely that adult community members will be "better" at imposing community-based sanctions, because they have more life experiences (i.e. with finances) than undergraduates enrolled at a private university.

Second, it would be a good idea to run a similar study using a videotaped (sentencing) hearing simulation. This change in methodology would increase the external validity of the study, and reduce the impact of demand characteristics (i.e. race). Furthermore, seeing a videotaped simulation may instill motivation to make serious (well-thought-out) sentencing selections, because the type of media is closer to reality. 
The results of this study revealed that nearly one-third of the participants believed that the victim had overreacted to the crime. This belief negatively affected sentencing decisions for the victims. Thus, it would be important to explore the factors that contribute to perceptions of the victim so we can know what types of victim impact statements are influential (and not detrimental) to each type of victim. Specifically, it would be interesting to run this study with female victims to see if a gender stereotype emerges. In other words, are participants more sympathetic to a "harm-statement" from a female victim, because it is more socially acceptable in this culture to hear women talk about emotional harm than it is for men.

It would also be important to examine different types of judge's instructions (beyond those used in this study) on how to interpret/use victim impact information. It could be that different wording or explicitly stated goals from the judge may facilitate the integration of victim impact statements into their sentencing decisions. Furthermore, it is also possible that the judge's instructions could be used to reduce potential victim stereotypes (e.g. gender). 
APPENDIX A: STIMULUS MATERIALS 


\section{STATEMENT OF FACTS}

James C. pled guilty to residential burglary and aggravated battery. On the evening of Tuesday December 19, 2006, James C. broke into the home of the victim with the intent of committing burglary. Prior to the home invasion James was reportedly drinking beer in a neighborhood pub. According to the other bar patrons, James was escorted from the bar highly intoxicated and in the middle of a heated argument with another patron over money James owed him due to the loss of a pool game. The defendant was very upset screaming, "Man, you know I don't have the money to pay you back now."

After leaving the bar the defendant got in the car and traveled several blocks when, according to him, he saw a house where there were no lights and no one appeared to be home. James then parked his car around the block and broke the window in the back door and let himself in. Motivated by the argument and his debt James began to look for any items of worth than could be pawned to pay his debt, and knocked over a lamp in the darkness.

As James got closer to the master bedroom of the house he soon realized that he was not alone in the home. The owner Michael R. was home alone in home with an illness while his family was at his oldest daughter's high school basketball game. The noise James made in the house had awoken Michael, and Michael got out of bed to get the phone to call 911 . While Michael was picking up the phone he was confronted by James who according to the victim was a large imposing figure reeking of alcohol. Michael recalled that James, the offender, screamed; "Don't!", and rushed toward him. Michael panicked and dropped the phone and the defendant picked the phone off the floor and struck Michael in the head with the phone hard enough to render the victim unconscious. The victim fell to the floor, blooding gushing from his skull.

James admitted that he did not know if the victim was alive or dead when he fled the scene of the crime. When the victim's family returned home from the basketball game they saw the shattered glass, and that the back door was open left open. Terrified for her safety and the safety of her children, the victim's wife gathered her children and ran to the neighbor's house and called 911. When the police arrived they found the victim unconscious in a small pool of blood. The victim was rushed to the hospital, and given a blood transfusion and stitches. Due to the nature of his head injury the victim spent nearly a week in the hospital.

Finger prints and DNA at the scene implicated the defendant who had two prior arrests for battery (July 1989, and December, 2005). 


\section{DEFENDANT BIOGRAPHY}

James B.

D.O.B: March 10, 1971

Age: 36

Race: African American

Sex: Male

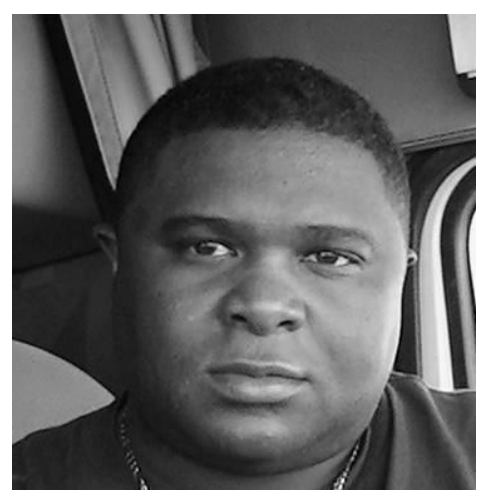

Family Attachments: Two children (daughter age 12, and son age 10) from a previous marriage. Both live with their mother in Chicago, IL. Mother, Chicago IL. Sister, brother in-law and two nieces of Chicago, IL. The defendant is required to pay child support of $\$ 500$ a month and has paid child support until he lost his full time job.

Defendant has not paid child support since September, 2006. Defendant is divorced, and is currently not dating anyone regularly.

\section{Employment at time of Arrest: Employed part-time}

Employment History: Employed for 15 years at Dominick's former produce manager. Fired September, 2006 for truancy and erratic behavior attributed to alcohol use/abuse. Has a part-time job as a store clerk at a local food market since November, 2006.

Prior Criminal History: Several minor traffic offenses. DUI in October, 2005. Two arrests for battery ( July 1989, and December, 2005).

Substance Use/Abuse: Defendant reports no former treatment for substance abuse. However, the defendant reports escalating alcohol use since his divorce in early 2004. Defendant admits that he "may have an alcohol problem" and desires treatment to limit his reliance on alcohol to get through "serious problems." He reports no use of illicit drugs. 
VICTIM IMPACT STATEMENT (SENTENCE RECOMMENDTION ONLY) RACE MANIPULATIONS

Dear Ladies and Gentlemen of the Jury,

First, I would like to thank the court for the opportunity to share a sentence recommendation. Due to the severe pain and suffering that I incurred as a result of my attack last December, I suggest that James B. receive a very severe prison sentence and be required to work to pay me back for my psychological, medical, and property damages.

Sincerely,

Michael R.
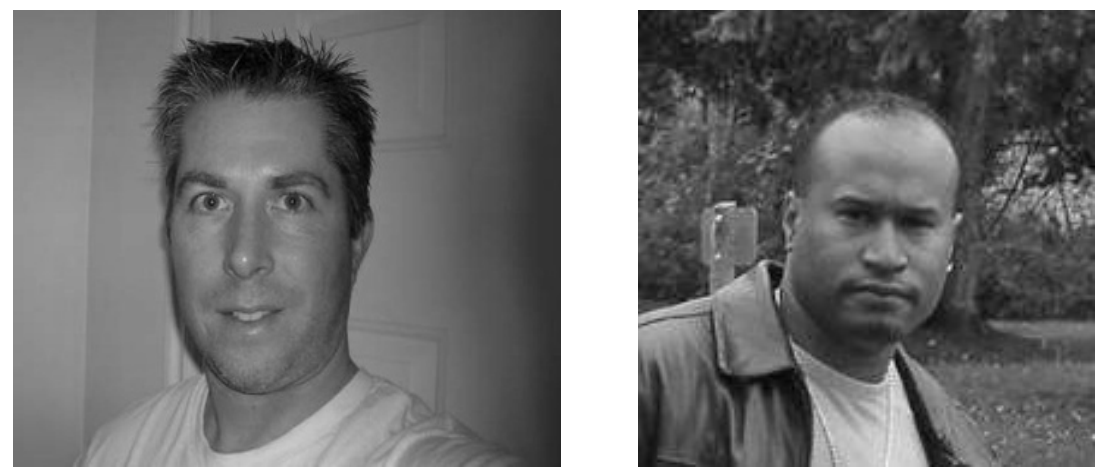


\section{VICTIM IMPACT STATEMENT (HARM STATEMENT)}

Dear Ladies and Gentlemen of the Jury,

I would first like to thank the court for the opportunity to address you today.

The pain caused by James B. goes far beyond the immediate physical injuries that I suffered at the time of the burglary and his attack on me. While the physical pain that I incurred was severe, fractured skull and a severe concussion, the physical pain was far less debilitating than the psychological, emotional, and financial trauma that resulted from my attack and robbery this past December.

I once felt safe and secure in my home. I once felt that I could provide a safe and secure environment for my family - protect them. I no longer feel that this is possible. As a result, I feel that I am somehow less of a man, a husband, a father, and provider. These insecurities have mounted from sadness to a full blown depression. I am now on medication for anxiety and depression. These feelings of inadequacy have caused problems in my marriage, and recently my wife and I have been attending counseling. My three children cry, because they think we are getting a divorce.

I wake up several times during at the night, thinking that I hear the sound of glass breaking, panicking, because I think someone is breaking in. Recently, I have looked into a home security system. However, the costs of these systems are quite expensive. I am not sure that I can afford it, especially since I still have $\$ 10,000$ worth of medical bills to pay off. The added financial burden that has occurred as a result of the attack and robbery has made it nearly impossible for me to afford to purchase a security system that I feel I need to protect my family. This only adds to my anxiety and depression.

I am a psychological wreck, I constantly fear for my life. Anytime the door slams, the phone rings, or a dish is dropped I get a sick feeling in the pit of my stomach. I suffer from nightmares of my brutal attack. Anytime someone is following me on the street I constantly turn around fearing that he will attack me, and leave me for dead. I find it difficult to feel safe and comfortable anywhere, home, work, or any public place.

Perhaps the worst part about this whole horrible ordeal is that my attack and hospitalization occurred a week before Christmas, and I spent Christmas in the hospital. We were supposed to travel to my mother's in Ohio for the holidays, which we were unable to do. My wife and I were forced to return many of the gifts we bought for the children, in order to pay some of the medical bills. Instead of a big family Christmas dinner, my family and I ate in the hospital cafeteria on Christmas day.

There is no way to quantify the damage that the attack and burglary has caused my family and me. The emotional and psychological damage that I have suffered have been extensive and have caused problems in my daily functioning. I no longer feel like the man I used to be, confident and proud. I now am only a shell of the person I used to be. The attack has caused irreparable damage to not only my self-esteem, but to my most important relationships with my wife and my children. It is impossible to equate my pain and suffering with an appropriate prison sentence for the defendant, since I will never be the same person as a result of his actions. For this reason, I recommend that James B. receive a very severe prison sentence and be required to work to pay me back for my medical, psychological, and property damages.

Sincerely, Michael R. 
JUDGE'S INSTRUCTIONS (NO EXPLICIT VIS GUIDANCE)

James B. has pled guilty to burglary and aggravated assault. Upon consideration of all the evidence you have read, you shall fix the defendant James B.'s punishment in the penitentiary for a specific term; assign him to probation for a fixed term; impose a fixed amount for restitution for his crimes; or fixed hours of community service. You may select any of the above, or you may select a combination of the above punishments. When you have decided on the proper punishment, you shall fill in the appropriate spaces on the Questionnaire form, and return the verdict to the court. (Adapted from: Ark. Model of Criminal Instructions 2d 9102 \& Va. Model Criminal Instructions: No. P44$100)$.

\section{JUDGE'S INSTRUCTIONS (EXPLICIT VIS GUIDANCE)}

James B. has pled guilty to burglary and aggravated assault. Upon consideration of all the evidence you have read, you shall fix the defendant James B.'s punishment in the penitentiary for a specific term; assign him to probation for a fixed term; impose a fixed amount for restitution for his crimes; or fixed hours of community service. You may select any of the above, or you may select a combination of the above punishments. When you have decided on the proper punishment, you shall fill in the appropriate spaces on the Questionnaire form, and return the verdict to the court.

Victim impact evidence is intended to remind you as the sentencer that just as the defendant should be considered as an individual whose burglary and subsequent attack may represent unique damages to society and his family. This (input/evidence: depending on condition?) is simply another method of informing you about the specific harm caused by the crime in question. You may consider this evidence in determining an appropriate punishment. (Adapted from: Cargyle v. State, 1995, pp. 828-829). 
APPENDIX B: QUESTIONNAIRE 


\section{PUBLIC VIEWS OF SENTENCING}

1. If you were able to sentence the offender, which sentencing option would you choose?

Four years on Straight Probation - offenders lives at his residence in the community and his required to comply with the conditions of probation that include not committing additional crimes, not using illegal drugs or alcohol, obtaining or maintaining employment, and attending at least two regularly scheduled appointments at the probation office with a probation officer who checks on his compliance. The probation officer also visits the offender at unscheduled time at the offenders' home once every two months. Officers verify residence and employment once every month and arrest records are checked once every three months. Offenders pay probation fees for supervision. Other conditions of probation can also be added including drug testing, community service, mandatory treatment, and restitution.

Four years on Intensive Supervision Probation - probation officers have more surveillance and contact with offenders compared to Standard Probation. Offenders proceed through three phases with the amount of surveillance decreasing: (a) Phase 1 - officer visits offender 5 times a week and offender has a curfew from 7:00 p.m. to 7:00 a.m. for the first 3 months; (b) Phase 2 - officer visits offender 3 times a week and offender has curfew from 9:00 p.m. to 7:00 a.m. for 3 to 6 months; (c) Phase 3 officer visits offender 3 times a week and offender has a curfew for 11:00 p.m. to 7:00 a.m.. All other conditions of standard probation apply, and offender is placed on standard probation after 24 months. Other conditions can be added.

Prison - offender resides in a prison. Treatment is rarely available.

Opportunity to work and earn money at low wages is available. Inmates have much difficulty finding law-abiding jobs once released.

1a. If you chose probation, check any of the conditions that you want the offender to comply with and indicate the length.

a. community service for hours

b. restitution to the victim in the amount of dollars

c.

d. jail time for months not to exceed 11 months.

mandatory treatment for weeks (specify type of treatment:

e. random drug and alcohol testing 
1b. If you chose prison, how many years in prison should the offender actually stay in prison? years

2. If you chose a probation sentence with conditions, how severe do you think it is relative to a prison term. What amount of time in prison is equivalent to the probation sentence with all requirements that you chose? I believe months or days in prison is equivalent to the community-based sentence I chose.

3. What is the purpose of this sentence? You may have more than one purpose, indicate how important each purpose is by assigning a percentage. If a purpose is not at all important, assign 0\%. All percentages across the eight options should total (add up) to $100 \%$. If only one purpose is important, assign $100 \%$ to that purpose and $0 \%$ to all other purposes.

a. ___ to warn other potential offenders that punishment is certain and severe for these types of crime so that they refrain from committing it

b. ___ to warn this offender that punishment is certain and severe for crimes so that he does not commit additional crimes

c. ___ to change this offender and make him a law-abiding productive citizen

d. ___ to punish this offender with a sanction that is equal to the harm that he caused society

e. ___ to keep this offender from committing further offenses while he is incarcerated

f. __ to repair the harm done to the victim and community and have the offender accept responsibility for his actions and be returned as a citizen in the community

g. ___ to reduce prison overcrowding through assigning a probation sentence

h. ___ other (please specify:

Total should equal $100 \%$

4. Which purpose in question 3 did you consider to be the most important in regards to the current case? Assign the number 1 to the most important and assign the number 2 to the second most important purpose

a.__ to warn other potential offenders that punishment is certain and severe for these types of crime so that they refrain from committing it

b.___ to warn this offender that punishment is certain and severe for crimes so that he does not commit additional crimes

c.__ to change this offender and make him a law-abiding productive citizen

d.___ to punish this offender with a sanction that is equal to the harm that he 
e. to keep this offender from committing further offenses while he is incarcerated

f.__ to repair the harm done to the victim and community and have the offender accept responsibility for his actions and be returned as a citizen in the community

g.___ to reduce prison overcrowding through assigning a probation sentence

h.___ other (please specify:

5. How severe is the sentence that you assigned?

\begin{tabular}{lllllcc}
\hline 1 & 2 & 3 & 4 & 5 & 6 & 7 \\
$\begin{array}{l}\text { Not at all } \\
\text { Severe }\end{array}$ & & & & & & $\begin{array}{c}\text { Extremely } \\
\text { Severe }\end{array}$
\end{tabular}

6. How confident are you in your sentencing recommendation?

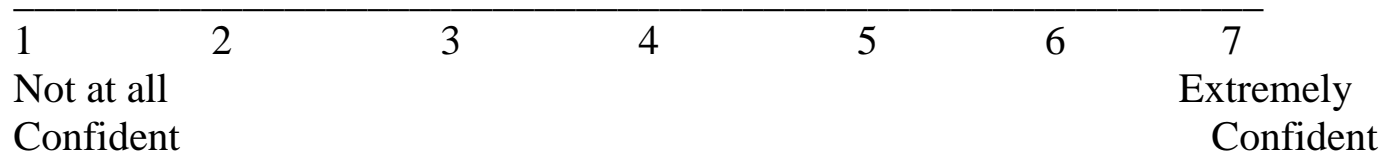

7. Did you consider any other sentence?

Yes _ No

8. If yes, what was the sentence and why didn't you use it?

9. Should offenders sentenced to prison,

be required to work at minimal jobs that do not help with finding work once released and not receive any wages for their work.

be required to work at a job that is consistent with their job skills and receive some wages for their work

be required to work at a job that is consistent with their job skills and have the opportunity to receive job training to become a skilled laborer (e.g., electrician, computer operator, computer technician) and receive wages have the opportunity to work at a job that the prison officials choose and that does not compete with citizens who are not in prison and receive wages have the opportunity to apply for several jobs that private companies offer 
to prisoners at lower than minimum pay of other citizens who are applying not be required or have the opportunity to work while in prison

9a. If offenders were required to work, what is the most important purpose for this requirement?

a.__ to change this offender and provide him with some job skills/experience

b.__ to punish this offender with hard laborer

c.__ to keep this offender busy so that he will not have time to commit further offenses while he is incarcerated

d.___ to repair the harm done to the victim through requiring restitution

e. __ to allow the offender to work so that he/she is required to pay child support for their children even if they are in foster care system

f. ___ to allow the offender to acquire a saving so that he can meet basic needs while looking for work upon his release

9b. What is the second most important purpose for requiring prison inmates to work?

(Do not check the one that you checked in 9a)

a.__ to change this offender and provide him with some job skills/experience

b.__ to punish this offender with hard laborer

c.___ to keep this offender busy so that he will not have time to commit further offenses while he is incarcerated

d.___ to repair the harm done to the victim through requiring restitution

e. __ to allow the offender to work so that he/she is required to pay child support for their children even if they are in foster care system

f. ___ to allow the offender to acquire a saving so that he can meet basic needs while looking for work upon his release

10. If the offender were sentenced to prison and required to work, how likely would this sanction repair the harm done to the victim and allow the offender to integrate back into the community as a productive citizen upon release from prison?

extremely more likely than a probation sentence moderately more likely than a probation sentence somewhat more likely than a probation sentence somewhat less likely than a probation sentence moderately less likely than a probation sentence extremely less likely than a probation sentence 
11. If prisoners are paid wages for their work for private companies while in prison, what percentage of their wages, if any, should be kept by the government to pay for their room and board while in prison? $\%$

12. If prisoners are paid wages for their work for private companies while in prison, should some of their earnings be used to pay back victims of violent crimes and property crimes?

Restitution should never be required of prisoners

Restitution should be required on a case-by-case basis

Restitution payments should always be required

13. How much restitution should offenders convicted of burglary be required to pay if all of the property stolen was recovered? dollars

14. If prisoners are paid wages for their work for private companies while in prison, should they be required to save any of their earnings to help them survive when they are released from prison? No Yes

15. Prisoners can earn money while in prison. For the list of items below, please rank the items from most importance (assign the number 1), second most important (number 2), third important (number 3), fourth (number 4), to least important (assign a number 5) on what the money should be spent on.

Room and board for prison stay

Restitution to victim of crime

Mandatory savings account for when offender is released

Money to buy clothing, snacks, cigarettes and other items allowed in prison Mandatory child support for children of prisoner

16. If inmates were allowed or required to work, how much should they be paid per hour for unskilled labor jobs? hour

16a. Should private companies be allowed to hire prison inmates to do work at cheaper wages and why or why not? No Yes

16a. Please explain your answer: 
16b. Please rate how fair each of the following sanctions are for this crime using the 7point scale where 1 is equal to not at all fair and 7 is equal to extremely fair.

Straight probation with mandatory substance abuse treatment Straight probation with mandatory substance abuse treatment and working to pay the victim $\$ 2,000$ in property and emotional damages Straight probation with six months in jail and working to pay the victim $\$ 2,000$ in property and emotional damages Intensive supervision probation with mandatory substance abuse treatment and working to pay the victim $\$ 2,000$ in property and emotional damages Intensive supervision probation with six months in jail and working to pay the victim $\$ 2,000$ in property and emotional damages Prison for 4 years Prison for 4 years and working to pay the victim $\$ 2,000$ in property and emotional damages

16c. How effective is each of the following sanctions at reducing the chance that the offender will commit another crime in the future? Use the 7 point scale where $1=$ not at all effective and 7 is equal to very effective.

Straight probation with mandatory substance abuse treatment

Straight probation with mandatory substance abuse treatment and working to pay the victim $\$ 2,000$ in property and emotional damages Straight probation with six months in jail and working to pay the victim $\$ 2,000$ in property and emotional damages Intensive supervision probation with mandatory substance abuse treatment and working to pay the victim $\$ 2,000$ in property and emotional damages Intensive supervision probation with six months in jail and working to pay the victim $\$ 2,000$ in property and emotional damages Prison for 4 years Prison for 4 years and working to pay the victim $\$ 2,000$ in property and emotional damages

17. How severe was the physical attack on the victim? Circle one:

$\begin{array}{rlllllll}1 & 2 & 3 & 4 & 5 & 6 & 7 \\ \text { Not very severe } & & & & & & \text { Extremely Severe }\end{array}$


18. Assume that the defendant is guilty but the jury finds him not guilty and lets him go free. What is the likelihood the defendant will commit a similar offense in the future?

$\begin{array}{ccccccc}1 & 2 & 3 & 4 & 5 & 6 & 7 \\ \text { Not Likely } & & & & & & \text { Very Likely }\end{array}$

19. Assume that the defendant is convicted and receives the sentence you imposed. What is the likelihood the defendant will commit a similar offense in the future?

$\begin{array}{ccccccc}1 & 2 & 3 & 4 & 5 & 6 & 7 \\ \text { Not Likely } & & & & & & \text { Very Likely }\end{array}$

20. How much physical harm did the victim receive?

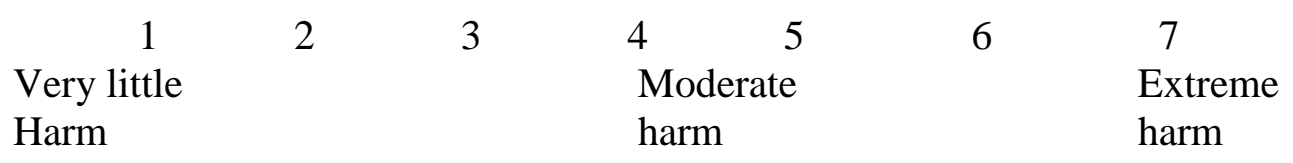

21. How much emotional harm did the victim receive?

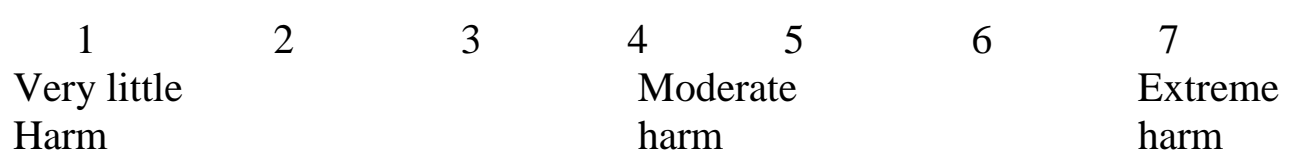

22. Please briefly state, state in your own words, the events and details of the crime you read about.

23. What is your opinion about why the offender committed the crime? Please assign a number using the scale below that indicates your opinion about what caused the offender to commit the crime. A number can be assigned more than once. (For example, if you feel that greed and mental illness are extremely important causes, you will assign both a number 7).

Not at all a cause

$\begin{array}{llllll}2 & 3 & 4 & 5 & 6 & 7\end{array}$

$$
<7>
$$

Extremely Important Cause 
Laziness

Drugs

Greed

Inadequate job opportunities

Financial stress

Mental illness

Lack of morals

Lack of appropriate family upbringing

Not concerned with the wellbeing of others

Other: Please Explain:

24. Using the scale below please rate your beliefs about the victim of the crime:

$\begin{array}{lllllll}1 & 2 & 3 & 4 & 5 & 6 & 7 \\ \text { Not at all } & & & & & & \text { Completely }\end{array}$

has feelings of guilt about being a victim

wants to be repaid for the property loss and emotional damage

has over-reacted to the crime experience

received serious emotional harm from the victimization deserves sympathy

I can understand the victim's reaction

had a reasonable reaction to the burglary and attack

has a severe emotional problem that was present before the crime

25. What was the race of the VICTIM in the case you read?

a. Caucasian

b. African-American

26. What is your age?

27. What is your race
a. African-American
b. Caucasian
c. Asian or Pacific Islander
d. Native Amerian
e. Other 


\section{REFERENCES}

Arkin, S.D. (1980). Discrimination and arbitrariness in capital punishment: An analysis of post-Furman murder cases in Dade County, Florida, 1973-1976. Stanford Law Review, 33, 75-97.

Baldus, D.C. \& Woodworth, G. (2003). Race discrimination and the legitimacy of capital punishment: Reflections on the interaction of fact and perception. DePaul Law Review, 53, 1411- 1468.

Booth v. Maryland, 482 U.S. 4961987.

Bowers, W.J. \& Pierce, G.L. (1980). Deterrence or brutalization: What is the effect of executions? Crime \& Delinquency, 26, 453-484.

Correll, J., Park, B., Judd, C.M., \& Wittenbrink, B. (2006). The police officers' dilemma: Using ethnicity to disambiguate potentially threatening individuals. Journal of Personality and Social Psychology, 83, 1314-1329.

Crime Victims' Rights Act of 2004, 18 U.S.C. $\$ 3771$

Diamond, S. \& Stalans, L.J. (1988). The myth in judicial leniency in sentencing. Behavioral Sciences and the Law, 7, 73-89.

Doble, J. \& Greene J. (2000). Attitudes Towards Crime and Punishment in Vermont: Public Opinion About an Experiment with Restorative Justice, John Doble Research Associates, Englewood Cliffs, NJ.

Doob, A.N. \& Roberts, J.V. (1988). Public punitiveness and public knowledge of the facts: Some Canadian surveys. In Walker, N., \& Hough, M. (eds), Public Attitudes Toward Sentencing, Cambridge Studies in Criminology, LIX, Gower, Aldershot, England, UK.

Doob, A.N., Sprott, J., Marinos, V. \& Varma, K. (1998). An Exploration of Ontario Residents' Views of Crime and the Criminal Justice System, Center of Criminology, Toronto.

Engel, R.S. (2005). Citizens perceptions of distributive and procedural injustice during traffic stops with police. Journal of Research in Crime and Delinquency, 42, 445481. 
Erez, E. (1994). Victim participation in sentencing: And the debate goes on. International Review of Victimology, 3, 17-32.

Feigenson, N., Park, J. \& Salvey, P. (1997). Effect of blameworthiness and outcome severity on attributions of responsibility and damage awards in comparative negligence cases. Law and Human Behavior,21, 597-617.

Finchman, F.D. \& Jaspers, J.M. (1980). Attribution and responsibility: From man-thescientist to man-as-lawyer. In Berkowitz, L. (ed.), Advances in Experimental Social Psychology, Academic Press, New York.

Fiske, S. \& Neuberg, S. (1990). A continuum of impression formation from category based to individuating processes. In M. Zanna (Ed.) Advances in Experimental Social Psychology. San Diego: Academic Press.

Gaertner, S.L. \& Dovidio, J. F. (1986). The aversive form of racism. Prejudice, Discrimination and Racism. San Diego, CA, US: Academic Press.

Greene, E. (1999). The many guises of victim impact evidence and effects of jurors's judgments. Psychology, Crime and Law, 5, 331-348.

Gromet, D.M. \& Darley, J.M. (2006). Restoration and retribution: How including retributive components affects the acceptability of restorative justice procedures. Social Justice Research, 19, 395-4332.

Gross, S.R. \& Mauro, R. (1984). Patterns of Death: An Analysis of Racial Disparities in Capital Sentencing and Homicide Victimization. Stanford Law Review, 37, 27153.

Hills, A. M., \& Thomson, D. M. (1999). Should victim impact influence sentences? Understanding the community's justice reasoning. Behavioural Sciences and the Law, 17, 661-671.

Hilton, J.L. \& von Hippel, W. (1990). The role of consistency in the judgment of stereotype relevant behaviors. Personality and Social Psychology Bulletin, 16, 430-488.

Immarigeon, R. (1986). Surveys reveal broad support for alternative sentencing. Journal of National Prison Project, 9, 1-4.

Karp, D.R. (2001). Harm and repair: Observing restorative justice in Vermont. Justice Quarterly, 18, 727-757. 
Kilpatrick, D.G., \& Otto, R.K. (1987). Constitutionally guaranteed participation in criminal proceedings for victims: Potential effects of psychological functioning. Wayne Law Review, 34, 7-27.

Leyens, J., Yzerbyt,V.L., \& Shadron, G. (1992). The social judgability approach to stereotypes. European Review of Social Psychology,3, 91-120.

Lind, E.A. (1994). Procedural justice and culture: Evidence for the ubigiotious process concerns. Zeitschift fur Rechtssoziologie, 15, 24-36.

Lind, E.A. \& Tyler, T.R. (1988). The Social Psychology of Procedural Justice. New York: Plenum Press.

Macrae, C.N., Milne, M.B., \& Bodenhausen, G.B. (1994). Stereotypes as energy saving devices: A peek inside the cognitive toolbox. Journal of Personality and Social Psychology, 66, 37-47.

Mande, M. \& Crouch, J. (1984). Crime in Colorado: 1984 Citizen Survey. Colorado Division of Public Safety, Division of Criminal Justice.

Mattinson, J. \& Mirrlees-Black, C. (2000). Attitudes to Crime and Criminal Justice: Findings From the 1998 British Crime Survey. Great Britain Home Office Research Development and Statistics DirectorateInformation and Publications Group United Kingdom.

Monteith, M. (1993). Self-regulation of prejudiced responses: Implications for progress in prejudice reduction efforts. Journal of Personality and Social Psychology, 65, 469-485.

Payne v. Tennessee (90-5721), 501 U.S. 808

Platania, J. \& Berman, G.L. (2006). The moderating effect of judge's instructions on victim impact statements in capital cases. Applied Psychology in Criminal Justice, 2, 84-101.

Pranis, K. \& Umbreit, M. (1992). Public Opinion Research Challenges Perception of Widespread Public Demand for Harsher Punishment. Minneapolis, MN: Citizens Council

Radelet, M.L. (1981). Racial Characteristics and the Imposition of the Death Penalty. American Sociological Review, 26, 918-927.

Roberts, J.V. \& Stalans, L.J. (2000). Public Opinion, Crime, and Criminal Justice. Westview Press: Boulder, CO.

Roberts, J.V. \& Stalans, L.J. (2004). Restorative sentencing: Exploring the views of the public. Social Justice Research, 17, 315-334. 
Secret, P.E. \& Johnson J.B. (1989). Racial differences in attitudes toward crime control. Journal of Criminal Justice, 17, 361-375.

Sweeney, L.T. \& Haney, C.W. (1992). The influence of race on sentencing: A metaanalytic review of experimental studies. Behavioral Sciences and the Law, 10, 179-195

South Carolina v. Gathers, 490 U.S. 8051989.

Thomson, RJ.. \& Zingraff, M.T. (1981) Detecting sentencing disparity: Some problems and evidence. American Journal of Sociology, 86, 101-126.

Unnever, J.D. (1982). Direct and organizational discrimination in the sentencing of drug offenders. Social Problems, 30, 212-235.

Unnever, J.D. \& Hembroff (1986). The seriousness of acts and social contexts: A test of Black's theory of the behavior of law. American Journal of Sociology, 93, 322347.

Yzerbyt, V.L., Schadron, G., Leyens, J. \& Rocher,S. (1994). Social judgeability: The impact of meta-informational cues on stereotypes. Journal of Personality and Social Psychology, 66, 48-55

Zatz, M.S. (1984). Race, ethnicity, and determinate sentencing: A new dimension to an old controversy. Criminology: An Interdisciplinary Journal ,22, 147-171. 
VITA

Mary E. Talbot was born and raised in Washington, IA. Before attending Loyola University Chicago, she attended the Coe College in Cedar Rapids, IA, where she earned a Bachelor of Arts in Philosophy, magna cum laude, in 2003. From 2004 to 2006, she also attended the University of Iowa to prepare for a graduate education in Psychology.

At Loyola, Mary served as a graduate reviewer for the journal Law and Human Behavior, and co-authored several Midwestern Psychological Association (MPA) posters, and delivered a talk at MPA entitled: "Can Training Increase Use of Baserate Information in Groups?" Mary also assisted in numerous research projects and has acted as consultant for a legal trial.

Currently, Mary is pursuing her PhD in Applied Social Psychology at Loyola University Chicago. She lives in Chicago, IL. 


\section{THESIS APPROVAL SHEET}

The thesis submitted by Mary E. Talbot has been read and approved by the following committee:

Loretta Stalans, Ph.D., Director

Professor of Criminal Justice \& Social Psychology

Loyola University Chicago

R. Scott Tindale, Ph.D.

Professor of Social Psychology

Loyola University Chicago

The final copies have been examined by the chair of the director of the thesis and the signature which appears below verifies the fact that any necessary changes have been incorporated and that the thesis is now given final approval by the committee with reference to content and form.

The thesis is therefore accepted in partial fulfillment of the requirements for the degree of Master of Arts. 






